University of South Florida

DIGITAL COMMONS Digital Commons @ University of @ UNIVERSITY OF SOUTH FLORIDA South Florida

$3-1-2010$

\title{
Developing a Technique That Predicts the Impacts of TDM on a Transportation System
}

CUTR

Follow this and additional works at: https://digitalcommons.usf.edu/cutr_nctr

\section{Recommended Citation}

"Developing a Technique That Predicts the Impacts of TDM on a Transportation System," National Center for Transit Research (NCTR) Report No. CUTR-NCTR-RR-2008-08, Center for Urban Transportation Research, University of South Florida, 2010.

DOI: https://doi.org/10.5038/CUTR-NCTR-RR-2008-08

Available at: https://scholarcommons.usf.edu/cutr_nctr/146

This Technical Report is brought to you for free and open access by the National Center for Transit Research (NCTR) Archive (2000-2020) at Digital Commons @ University of South Florida. It has been accepted for inclusion in Research Reports by an authorized administrator of Digital Commons @ University of South Florida. For more information, please contact digitalcommons@usf.edu. 
Prepared by

National Center for Transit Research

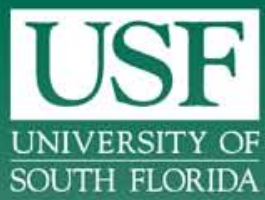

\section{Developing a Technique that Predicts the Impacts of TDM on a Transportation System}

March 2010

Final Report

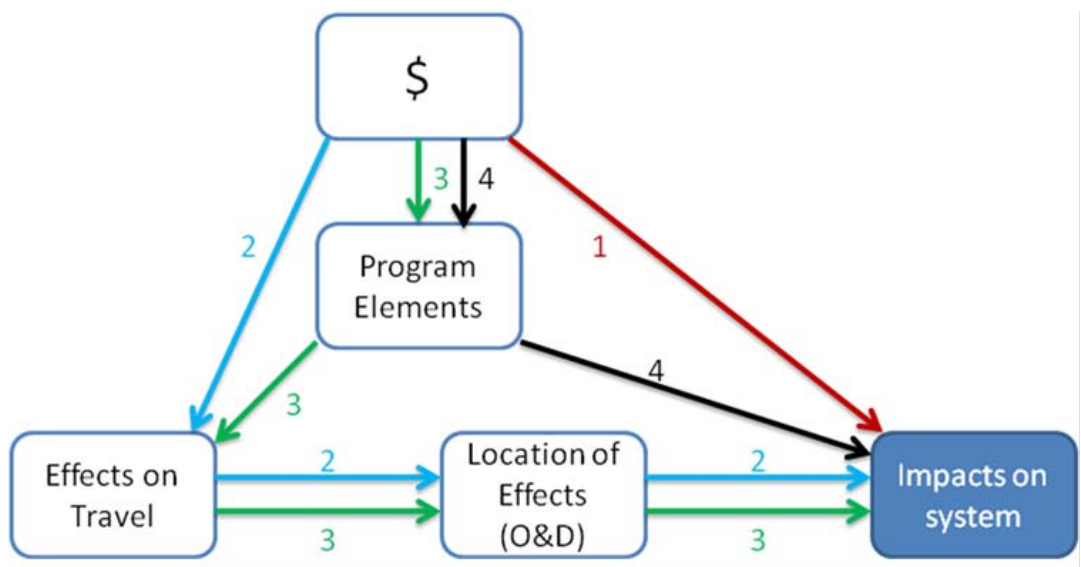

Florida Department of Transportation 


\title{
Developing a Technique that Predicts the Impacts of TDM on a Transportation System
}

\author{
Final Report
}

Prepared for

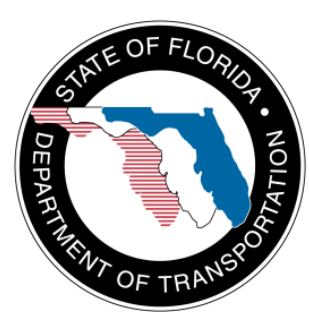

State of Florida Department of Transportation

Public Transit Office

605 Suwannee Street, MS 30

Tallahassee, Florida 32399-0450

Project Manager: Michael Wright

Prepared by

Philip L. Winters, Chanyoung Lee, Edward L. Hillsman, and Nevine Labib Georggi

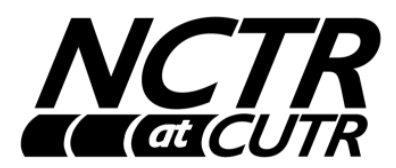

National Center for Transit Research

Center for Urban Transportation Research (CUTR)

University of South Florida

4202 East Fowler Avenue, CUT100

Tampa, Florida 33620-5375

March 2010

FDOT BDK85 WO 977-06 
The opinions, findings, and conclusions expressed in this publication are those of the authors and not necessarily those of the Florida Department of Transportation. 


\begin{tabular}{|c|c|c|}
\hline & 2. Government Accession No. & 3. Recipient's Catalog No. \\
\hline \multirow{2}{*}{\multicolumn{2}{|c|}{$\begin{array}{l}\text { 4. Title and Subtitle } \\
\text { Developing a Technique that Predicts the Impacts of TDM on a } \\
\text { Transportation System }\end{array}$}} & $\begin{array}{l}\text { 5. Report Date } \\
\text { February } 2010\end{array}$ \\
\hline & & 6. Performing Organization Code \\
\hline \multicolumn{2}{|c|}{$\begin{array}{l}\text { 7. Author(s) } \\
\text { Philip L. Winters, Chanyoung Lee, Edward L. Hillsman, and Nevine Labib } \\
\text { Georggi }\end{array}$} & $\begin{array}{l}\text { 8. Performing Organization Report No. } \\
\text { USF } 21177809\end{array}$ \\
\hline \multirow{2}{*}{\multicolumn{2}{|c|}{$\begin{array}{l}\text { 9. Performing Organization Name and Address } \\
\text { National Center for Transit Research } \\
\text { Center for Urban Transportation Research } \\
\text { University of South Florida } \\
4202 \text { E. Fowler Ave., CUT100 } \\
\text { Tampa FL } 33620\end{array}$}} & 10. Work Unit No. (TRAIS) \\
\hline & & $\begin{array}{l}\text { 11. Contract or Grant No. } \\
\text { FDOT BDK85 WO 977-06 }\end{array}$ \\
\hline \multirow{2}{*}{\multicolumn{2}{|c|}{$\begin{array}{l}\text { 12. Sponsoring Agency Name and Address } \\
\text { Florida Department of Transportation Research Center } \\
605 \text { Suwannee Street, MS30 } \\
\text { Tallahassee, FL } 32399\end{array}$}} & \multirow{2}{*}{\begin{tabular}{|l|} 
13. Type of Report and Period Covered \\
FINAL \\
14. Sponsoring Agency Code \\
\end{tabular}} \\
\hline & & \\
\hline \multicolumn{3}{|c|}{$\begin{array}{l}\text { 15. Supplementary Notes } \\
\text { FDOT Project Manager: Michael Wright, Commuter Assistance Program Manager, Office of Public } \\
\text { Transportation, FDOT }\end{array}$} \\
\hline \multicolumn{3}{|c|}{$\begin{array}{l}\text { 16. Abstract } \\
\text { Given declining resources, pressing problems, and environmental constraints, state departments of } \\
\text { transportation (DOTs) are increasingly motivated to manage peak demand of vehicle trips as a way to mitigate } \\
\text { congestion and improve overall performance of the highway system. Managing demand this way requires an } \\
\text { ability to predict the magnitude and geographic distribution of potential changes in travel behavior resulting } \\
\text { from steps taken at specific locations to manage transportation demand. It also requires an ability to build on } \\
\text { these predictions to estimate the impacts of implementing transportation demand management (TDM) } \\
\text { strategies on travel demand on a specific corridor. The research hypothesis assumed increases in employers' } \\
\text { expenditures for subsidies and incentives, in support of employees commute options program, will decrease } \\
\text { the drive-alone rate. If a strong relationship between expenditures and changes in mode split were established, } \\
\text { TDM programs can be incorporated more confidently as a congestion management option. The research } \\
\text { centered on the relationship between TDM effectiveness at the worksite level and employer-based TDM } \\
\text { program costs. Data collection efforts focused on the examination of thousands of employer trip reduction } \\
\text { plans submitted over many years and cost survey results of those employers with the goal of integrating the } \\
\text { information with the new TDM Assessment Procedure (TDMAP). TDMAP incorporates TDM into the } \\
\text { transportation planning process by modifying mode split tables to reflect the impact of implementing a } \\
\text { particular TDM strategy or mix of strategies in specific corridors over time. TDMAP consists of a set of } \\
\text { subroutines that integrate with NCTR/FDOT-developed TRIMMS@ } 2.0 \text {. Despite using the most comprehensive } \\
\text { data set from the State of Washington Commute Trip Reduction program, a strong relationship between } \\
\text { changes in expenditures for subsidies and incentives, and changes in the drive-alone rate could not be } \\
\text { established. The project concluded with developing a practical guide for collecting TDM cost data at the } \\
\text { worksite level and providing an example of the TDMAP. }\end{array}$} \\
\hline $\begin{array}{l}\text { 17. Key Word } \\
\text { Transportation demand management, } \\
\text { TDM, evaluation, B/C, cost- } \\
\text { effectiveness, TDM program costs }\end{array}$ & $\begin{array}{l}\text { 18. Distribution Statement } \\
\text { Available to the public through the National Te } \\
\text { Royal Road, Springfield VA 22161, (703) 487-4€ } \\
\text { NCTR website at http://www.nctr.usf.edu }\end{array}$ & \\
\hline 19. Security Classif. (of this report) & 20. Security Classif. (of this page) & \begin{tabular}{|c|} 
21. No. of Pages \\
54
\end{tabular} \\
\hline
\end{tabular}

Form DOT F 1700.7 (8-72) 


\section{Acknowledgements}

Center for Urban Transportation Research (CUTR) Research Team

Philip L. Winters, Director, Transportation Demand Management (TDM) Program, CUTR

Chanyoung Lee, Senior Research Associate, ITS, Traffic Operations, and Safety Program, CUTR

Edward L. Hillsman, Senior Research Associate, TDM Program, CUTR

Nevine Labib Georggi, Senior Research Associate, TDM Program, CUTR

Florida Department of Transportation (FDOT) Project Manager

Michael Wright, Commuter Assistance Program Manager, Office of Public

Transportation, FDOT

The research team is grateful for the support of the following individuals, who provided valuable input to enhance this research:

Robert Ancar, Office of Policy and Performance, New York State DOT

Colin Black, Contemporary Transport Ltd, Tonbridge, U.K.

Lori Diggins, LDA Consulting, Washington, D.C.

Matt Hansen, Supervisor of Market Development, King County Metro, WA

Bill Loudon, DKS \& Associates, Oakland, CA

Wendy Morgan, Center for Transportation and Environment, Atlanta, GA

Bill Roach, Market Development for King County Metro (retired), WA

Eric Schreffler, Transportation Consultant, ESTC, San Diego, CA

Grant Zammit, Traffic Management and System Operations, FHWA, Atlanta, GA 
Given declining resources, pressing problems, and environmental constraints, state departments of transportation (DOTs) are increasingly motivated to manage peak demand of vehicle trips as a way to mitigate congestion and improve overall performance of the highway system. Managing demand this way requires an ability to predict the magnitude and geographic distribution of potential changes in travel behavior resulting from steps taken at specific locations to manage transportation demand. It also requires an ability to build on these predictions to estimate the impacts of implementing transportation demand management (TDM) strategies on travel demand on a specific corridor.

The research hypothesis assumed increases in employers' expenditures for subsidies and incentives, in support of employees commute options program, will decrease the drive-alone rate. If a strong relationship between expenditures and changes in mode split were established, TDM programs can be incorporated more confidently as congestion management option. The research centered on the relationship between TDM effectiveness at the worksite level and employer-based TDM program costs. Thousands of before/after employer trip reduction plans collected over the past ten years from the states of Washington, California, and Arizona were targeted as the source of the data. Specifically, the research team sought data from these sources because it was believed that each recorded changes in travel behavior, reported employer actions to reduce trips, and contained employer expenditure data collected in the same manner. However, only the Commute Trip Reduction (CTR) data from Washington collected all three sets of survey data (employer, employee, and cost). The others had not maintained the level of detail needed to use them in this project's analysis. For example, staff at one of the programs also indicated that although they had collected data on employer expenditures in the past, they quit collecting it because they did not consider it reliable. Washington CTR data has the only complete data set, but even this data set has significant limitations.

The goal was to integrate the cost information with the new TDM Assessment Procedure (TDMAP). TDMAP incorporates TDM into the transportation planning process by modifying mode split tables to reflect the impact of implementing a particular TDM strategy or mix of strategies in specific corridors over time. TDMAP consists of a set of subroutines that integrate with National Center for Transit Research (NCTR)/FDOT-developed TRIMMS@ 2.0. Despite using the most comprehensive data set from the State of Washington Commute Trip Reduction program, a strong relationship between changes in expenditures for subsidies and incentives, on the one hand, and changes in the drive-alone rate, on the other, could not be verified. The project concluded with developing a practical guide for collecting TDM cost data at the worksite level and providing an example of the TDM Assessment Procedure. 


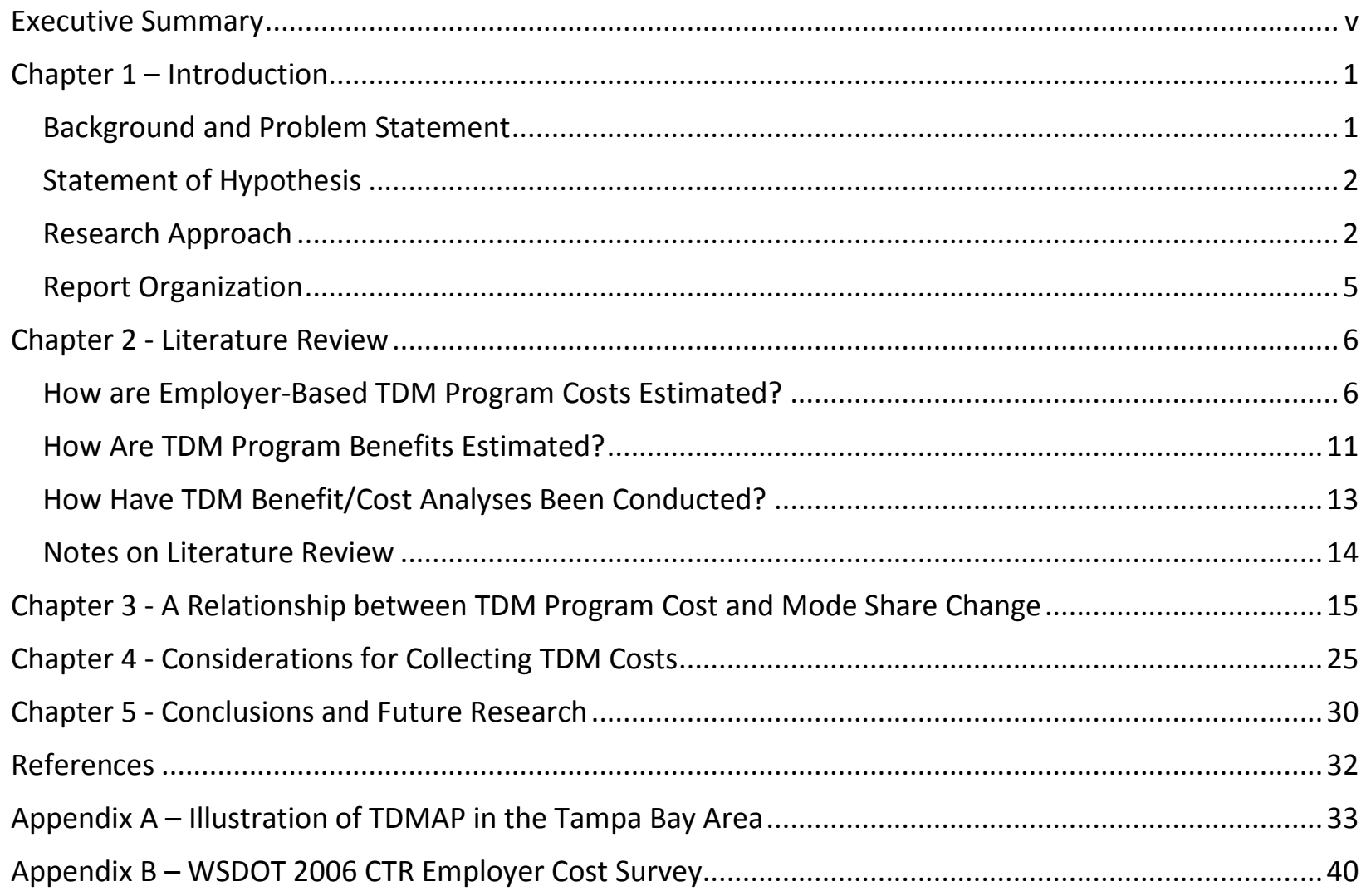


Figure 1 - FDOT Forecasting Technique and WSDOT TDM Off-Model ................................................. 3

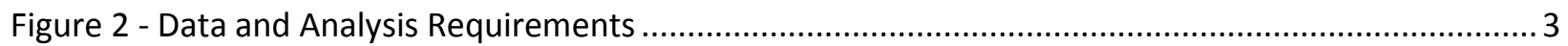

Figure 3 - Conceptual Frameworks for Integrating a B/C TDM Analysis Technique

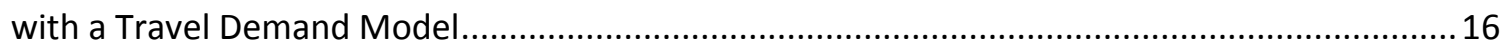

Figure 4 - Drive-Alone Mode Share Change by Program Start Year .................................................21

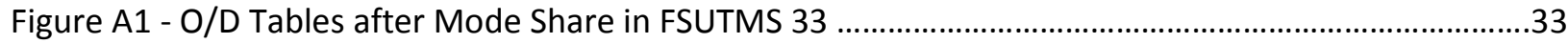

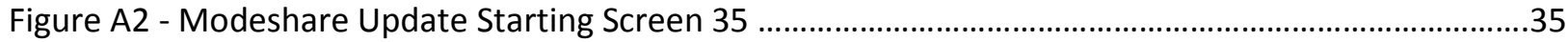

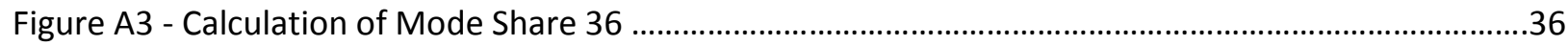

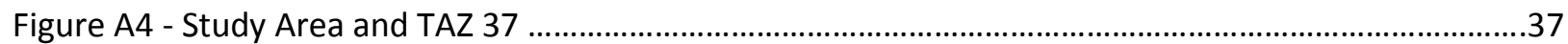

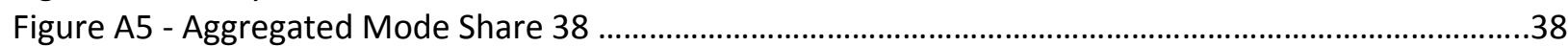


Table 1 - Total and Average Committed Expenses by Category/Group ....................................................8

Table 2 - Average Annual Budgeted Expense per Employee by Employer Type ......................................9

Table 3 - District Calculated Absolute Cost-Effectiveness ............................................................. 10

Table 4 - Mode Share Change vs. TDM program Cost per Employee ....................................................18

Table 5 - Example of Cost Data and Program Data .....................................................................

Table 6 - Number of Participating Employers by Survey Cycle and Starting Year of Program ................. 20

Table 7 - Drive-Alone Mode Share Changes between Survey Cycles..................................................21

Table 8 - Number of Subsidy Programs by Employer and Survey Cycle ...............................................24

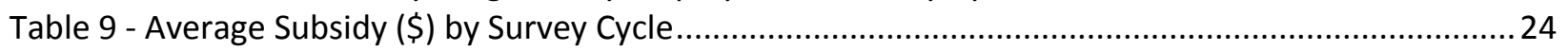

Table 10 - Mode Share by Survey Cycle .................................................................................. 24 
Given declining resources, pressing problems, and environmental constraints, state departments of transportation (DOTs) are increasingly motivated to managing peak demand of vehicle trips as a way to mitigate congestion and improve overall performance of the highway system. Managing demand this way requires an ability to predict the magnitude and geographic distribution of potential changes in travel behavior resulting from steps taken at specific locations to manage transportation demand. It also requires an ability to build on these predictions to estimate the impacts of implementing transportation demand management (TDM) strategies on travel demand on a specific corridor.

Some evaluation of the effects of demand management estimation is possible via modeling, but this work has been done retrospectively (what happened) rather than predicatively (what if). Multimodal, operational, and construction mitigation planning all have tools that estimate the effects of various options for improving a transportation system's performance prior to implementation. An example of such a tool, one that has been used by the Intelligent Transportation Systems (ITS) community, is ITS Deployment Analysis System (IDAS) software. IDAS is used to compare ITS deployments by estimating benefit/cost $(B / C)$ ratios for various alternatives. Because TDM planning lacks such a quantitative tool, it can be overlooked as a viable option or supplementary program when searching for solutions to mitigate traffic congestion, construction, or air quality. If available, such a tool/technique will facilitate consideration of TDM to provide the same level of benefit as other approaches. A sketchplanning tool that interfaces with travel demand models would facilitate the estimation of the impacts of deploying TDM strategies on delay, speed, and travel time through specific corridors.

This study researched ways to incorporate TDM strategies in software such as IDAS that would allow state, regional, and local transportation planners and decision-makers to actively consider TDM strategies as a congestion mitigation tool, just as practiced with ITS deployments that are designed to increase the efficiency of managing traffic capacity. The expectation was that this National Center for Transit Research (NCTR)/FDOT project would help analysts identify and choose the most cost-effective mix of program elements for improving traffic and air quality conditions in a corridor and see how the cost and mix varies with the desired level of change.

Given that there is very limited data available on costs of individual TDM program elements, and on how those expenditures (as opposed to the elements) affect travel behavior, the research team then shifted its focus to look at how data on program expenditures have been collected, and how the collection of such data might be improved to support development of a database with which to estimate the benefit-cost ratio of TDM programs. TDM programs involve expenditures to administer the programs, and direct expenditures for TDM services (particularly of financial incentives and subsidies, but also for services such as emergency ride home), as well as costs to the consumer (commuter). Some costs are paid by public agencies, 
while others are paid by employers. The fact that many TDM programs involve partnerships between employers, public agencies, and non-profit organizations further complicates the difficulty of obtaining data on costs.

\section{Statement of Hypothesis}

An increase in an employer's expenditures for subsidies and incentives in support of employees commute options program will decrease the drive-alone rate. While the Commute Trip Reduction (CTR) Cost Survey was intended solely to report the total costs that employers incurred in complying with the CTR program, the survey has the potential for revealing which strategies are the most cost-effective when combined with an assessment of effectiveness.

If a strong relationship between increasing expenditures and changes in mode split can be established, TDM programs can be incorporated confidently among alternatives considered in the analysis of the cost-effectiveness of various congestion management options.

Research Approach

This NCTR/FDOT project was conducted in parallel with a separate but complementary project for the Washington State Department of Transportation (WSDOT) titled "Measuring the Impact of Employer-Based TDM Strategies on Transportation System Performance" (WSDOT Contract GCA57030). The same researchers worked on both projects simultaneously to pool resources, particularly the expertise of the assembled peer review panel that was required for the WSDOT project. Two web meetings were conducted in January and September 2009. The expert members of the review panel were updated on the progress of both research studies and were consulted on issues when the research team members solicited input and guidance on both projects. Figure 1, presented to the review panel in the introductory web meeting, highlights how tasks of the two projects were interconnected.

At a sketch-planning stage, the question to be answered is, "Is a particular strategy (ITS, TDM, construction) cost-effective in correcting the situation?" To answer this, one would like a tool that estimates the impact that spending an available amount of money on a particular strategy would have on the situation. The ideal, simplest relationship is shown by the red lines in Figure 2 , numbered " 1 " in the figure ("dollars in, results out"). If this relationship is not known, then an alternative is a tool that first estimates the effects of spending an available amount of money on travel behavior, then estimates where these effects would occur, and then what this means in terms of the situation (congestion). This alternative is shown by the blue lines, numbered "2." Operationally, such a tool would be more tightly integrated with a traditional four-step regional transportation modeling system than would be the simpler model represented by the red line (" 1 "). 


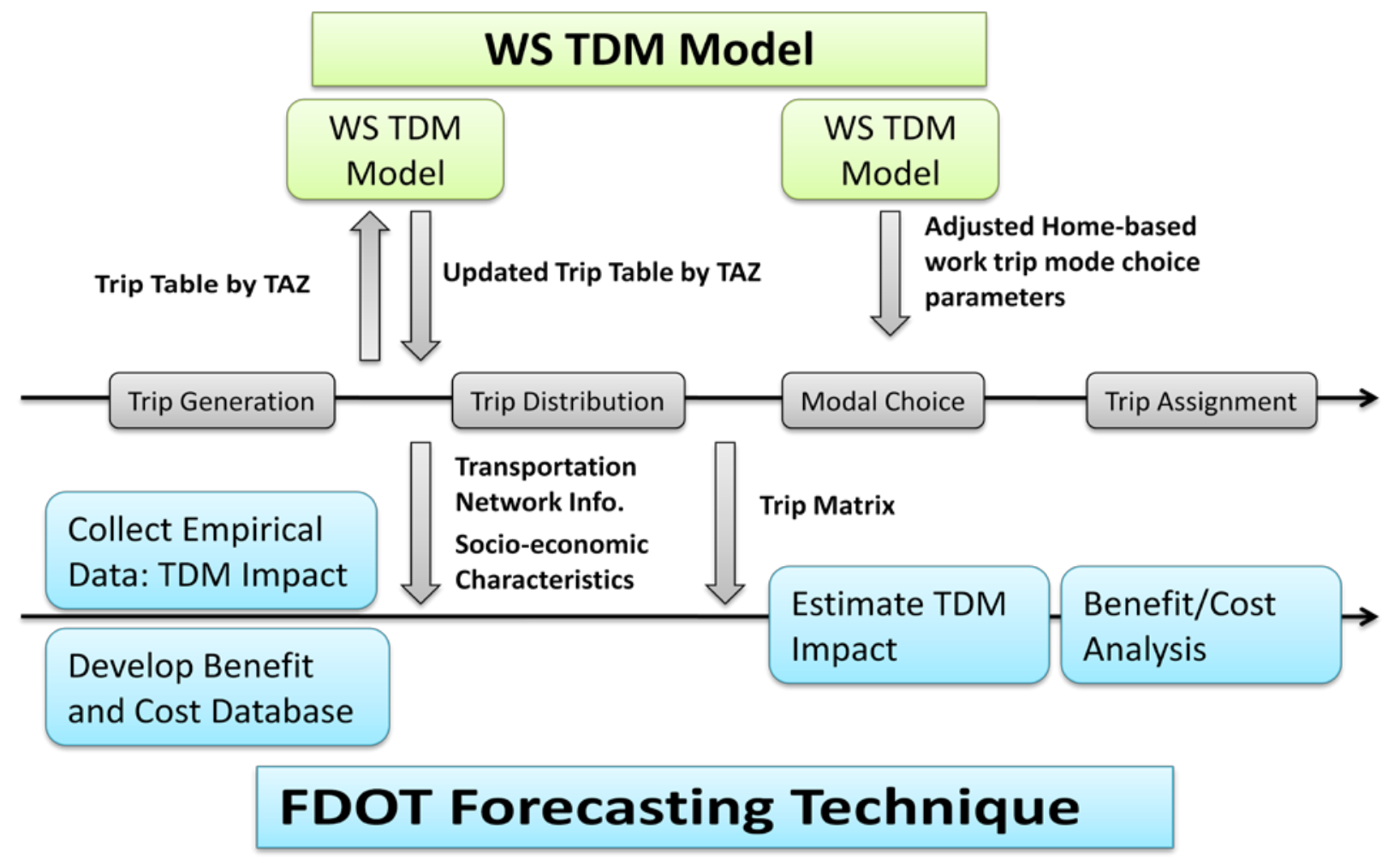

Figure 1 - FDOT Forecasting Technique and WSDOT TDM Off-Model

It is helpful to consider the relationships between different types of data and different stages of planning, as shown in Figure 2. In all stages, there is a situation that an agency would like to change (in this instance, congestion on a part of the transportation system).

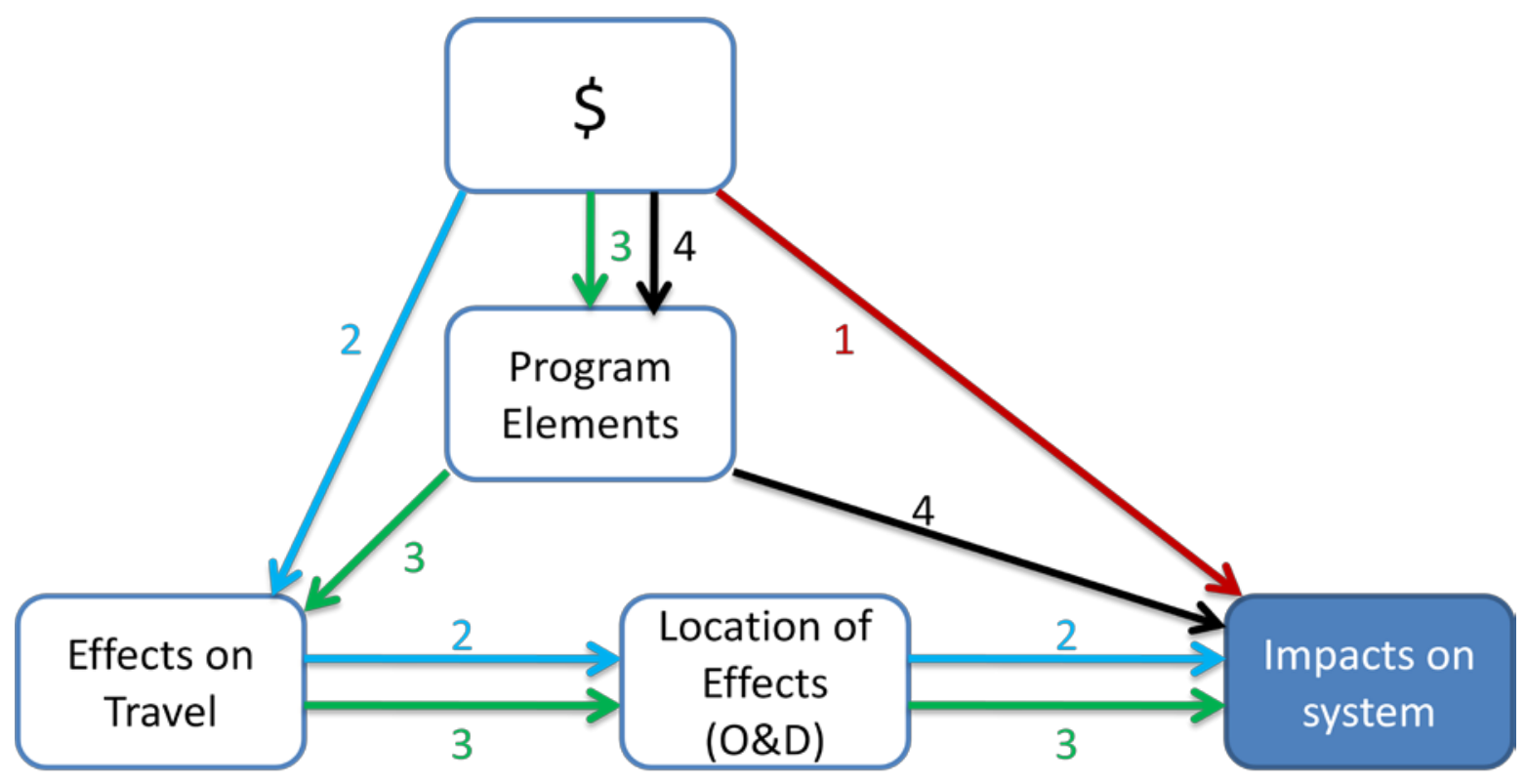

Figure 2 - Data and Analysis Requirements 
Once past the sketch-planning stage, the question becomes, "Exactly what steps need to be taken (programs to be implemented, technologies to be installed, etc.) to achieve the estimated impacts?" To answer this, one would like a tool that links an allowable budget (expenditures) to actions or programs and their effects. This relationship is shown by the green lines in Figure 2, numbered "3."

The ideal situation would be to have a model that, instead of starting with an allowable budget, would ask, "Given the level of impact desired in a corridor, what combination of TDM programs, ITS technologies, etc. would achieve this level of improvement for the least cost?" For sketch planning, this would need the relationship shown by the black lines in Figure 2, numbered "4." For operational planning, the need would again be for something like the relationship in green (" 3 "), but the independent variable would be the desired level of impact rather than the allowable expenditures (arrows reversed from what appears in the figure).

For the sketch-planning tool to have credibility, relationships 1 or 2 need to be reasonably consistent with relationship 3. To develop a sketch-planning tool requires data on all four of the unshaded boxes in the figure, to determine whether the tool is credible, even though once the tool has been developed, the tool itself might only require relationship 1.

Since the research was centered on the relationship between TDM effectiveness and employerbased TDM program costs, data collection efforts were focused on the following resources:

- The thousands of trip-program surveys collected in the states of Washington, California, and Arizona that recorded travel behavior, employer actions to reduce trips, and employer expenditures.

- Infrastructure (such as high occupancy vehicle lanes or express bus facilities) for alternative modes collected by state DOTs and transit agencies.

As originally planned, the analysis would have been conducted for several TDM programs in addition to Washington State's CTR program. However, the other programs either had not collected all three sets of data (describing employer programs, employer expenditures, and employee commuting), or they had not maintained the level of detail needed to use the data in this project's analysis, or they no longer had the data available for consistent time periods. Staff at one of the programs also indicated that although they had collected data on employer expenditures in the past, they quit collecting it because they did not consider it reliable. This left the Washington CTR data as the only complete data set. Even this dataset has significant limitations. It must be understood that, when working with any of the data collected by mandated trip reduction programs, the data were collected to manage and evaluate the programs that collected them. For the most part, the data collection designs of these programs were not developed to support research or analysis beyond the goals of their evaluation plans. The limitations as well as the steps taken to eliminate inconsistencies in the CTR data set are highlighted in Chapter Three.

For the CTR program employers as a whole, the employee commute data show that, on average, the largest reductions in drive-alone share occurred in the first two years of the 
program. Beyond that, a clear relationship between changes in expenditures for subsidies and incentives, on the one hand, and changes in the drive-alone rate, on the other, could not be established.

At this point, the research team examined some of the difficulties they had encountered in working with the available cost data, and shifted the focus to look at how data on program expenditures have been collected, and how the collection of such data might be improved to support development of a database with which to estimate the benefit-cost ratio of TDM programs. TDM programs involve expenditures to administer the programs, and direct expenditures for TDM services (particularly of financial incentives and subsidies, but also for services such as emergency ride home), as well as costs to the consumer (commuter). Some costs are paid by public agencies, while others are paid by employers. The fact that many TDM programs involve partnerships between employers, public agencies, and non-profit organizations further complicates the difficulty of obtaining data on costs. The Washington CTR data on program costs covered only expenditures by employers. Information on expenditures by public agencies is harder to come by, in a way that can be linked to specific program elements.

\section{Report Organization}

Chapter 2 investigates ways that TDM impacts have been assessed and how the programs' costeffectiveness measures have been estimated. Chapter 3 presents the methodology used to determine the relationship between expenditures of employer-based TDM programs and changes in mode split over time. The chapter also highlights challenges with modeling the relationship and reasons why they occurred. Based on research findings, Chapter 4 proposes another way of reporting employer expenditures by contrasting the status quo and more practical and beneficial approaches of collecting the data. The final chapter discusses the results of the findings of this research study and makes recommendations for future research. Appendix A provides an illustration of the TDMAP using the Florida Standard Urban Transportation Model Structure (FSUTMS) as an exercise in applying the process that captures mode split before and after TDM programs are applied and incorporates the changes into the four-step travel demand model. 
The focus of the research was to provide a benefit/cost analysis element in a sketch planning tool such as IDAS. To develop that element, costs and benefits data had to be collected and analyzed. Compiling TDM costs and benefits documented in published reports was not a straightforward task. To simplify the task, answers to specific questions that would help in assembling a $B / C$ database were investigated. This section of the report documents how the following questions are answered in the body of available literature:

- How are employer-based TDM program costs estimated?

- How are benefits estimated?

- How have TDM benefit/cost analysis been conducted?

How are Employer-Based TDM Program Costs Estimated?

Several attempts have been made to calculate the costs of employer-based TDM programs, including attempts to link those costs with performance, as discussed below.

In 1994, the Federal Highway Administration (FHWA) published several reports on TDM to provide technical assistance for planning, implementing, operating, and/or monitoring TDM activities [1]. The reports served to educate and provide guidance in the development of TDM programs. One particular report, "Overview of Travel Demand Management Measures," pointed out that reducing single-occupant vehicles (SOVs) would render cost savings to three major TDM stakeholders: society at large, employers, and individual travelers.

The cost to society was defined as the cost of accommodating an additional SOV commute trip on a congested highway and was estimated to be $\$ 6.75$ per daily one-way 10.5 -mile trip (\$13.50 per day). If this SOV trip were shifted to transit, the cost to society would be $\$ 4.10$ for a trip of the same length; for a carpool or vanpool, the public cost would be reduced to $\$ 2.70$ and $\$ 0.56$ per trip, respectively. The average direct cost to employers to reduce a one-way vehicle trip was $\$ 1.33$ (based on 22 employers studied); the net cost for the employer was a savings of $\$ 0.43$ per one-way trip for every vehicle trip reduced (considering, for example, the need for more parking spaces eliminated). The cost saving to the individual also would be substantial, for example, in the case of vanpooling, where costs of gas, parking, and wear/tear on the vehicle is shared by the 12 occupants.

Southern California was the epicenter for research into TDM effectiveness in the early 1990s due to its air-quality-motivated trip reduction requirement (Regulation XV), which required employers with over 100 employees in the morning peak period to develop trip reduction plans. The TDM agency for that area conducted a study to determine the expenditures employers would need to make to increase average vehicle ridership (AVR). They selected the employers with the largest increase in AVR from the 769 employers that had submitted at least two employer trip reduction plans. From the 37 responding employers, it was reported that 
the annual expenditure averaged $\$ 29,000$, with a range of $\$ 1,500$ to $\$ 133,400$. The peremployee annual cost ranged from $\$ 6$ to $\$ 450$ with a mean of $\$ 70$ [1].

In a subsequent study, the accounting firm of Ernst and Young was commissioned by the South Coast Air Quality Management District to estimate the annual compliance costs and the change in commute trips associated with those expenditures. Over 5,700 surveys were distributed, and Ernst and Young achieved a 19 percent response rate. The survey asked employers to separate costs into four categories: Employee Transportation Coordinator, Trip Reduction Plan Preparation and Approval, Plan Implementation, and Other Costs. The firm concluded that there was a weak correlation between the individual regulated sites costs per employee and changes in employee commute trips. Like the earlier study, a wide range of costs was reported (from less than $\$ 25$ to more than $\$ 750$ per employee trip reduced per year).

A follow-up study with personal interviews and hands-on guidance in the completion of the forms was made to attempt to understand the variation [2]. A sample of 20 employers, including 10 of the 50 employers reporting the highest costs and 5 each from the middle and lower strata, was drawn. It was found that the majority of the companies with the highest costs had overstated their costs. When the costs were recalculated, the total cost among this sample of 20 employers had decreased by about 50 percent.

This NCTR study is focused on employer cost estimation. Maricopa County, Arizona, provides some insights into how costs of employer-based TDM programs are estimated. In the mid1980s, a federal judge directed the State of Arizona to write a State Implementation Plan (SIP) to comply with the National Ambient Air Quality Standards (NAAQS) for carbon monoxide. In response to the order, the Arizona Legislature passed the 1988 Air Quality Bill, which mandated a Trip Reduction Program (TRP) for employers and schools in Maricopa County. Employers and schools were asked to reduce single-occupant vehicle trips and/or miles traveled to the work site by 10 percent per year for a total of five years, and then 5 percent for three additional years or until a 60 percent rate of SOV travel was reached. Today, the county ordinance applies to most employers and schools with 50 or more employees and/or driving-age students.

In 2005, the Maricopa County Trip Reduction Program reported the expenses by a stratified sample of employers subject to the ordinance [3]. However, the expenditures reported were not tied to changes in mode split or distributed between those who met the objective versus those who were striving to meet it. Table 1 presents the total and average expenses for different organization sizes.

In 2007, 343 out of 972 employers that were in the third year or later of the program were surveyed. Rather than report results by size, as in 2005, Maricopa County reported by industry type (Table 2). These employers had a total committed budget of over $\$ 2.75$ million, an average annual expenditure per employee of $\$ 12.86$, with a range of $\$ 0.17$ at a school district to $\$ 223.95$ at a law firm. Again, no information was reported on the relationship between expenditures and results [4]. 
Table 1 - Total and Average Committed Expenses by Category/Group

\begin{tabular}{|c|c|c|c|c|c|c|c|}
\hline Group & A & B & $\mathbf{C}$ & D & $\mathbf{E}$ & $\mathbf{F}$ & G \\
\hline $\begin{array}{l}\text { Organization Size (number of qualifying } \\
\text { employers and/or students) }\end{array}$ & $50-100$ & $\begin{array}{c}101- \\
200\end{array}$ & $201-500$ & $\begin{array}{l}501- \\
1,000\end{array}$ & $\begin{array}{c}1,001- \\
5,000\end{array}$ & $\begin{array}{l}5,001 \text { or } \\
\text { more }\end{array}$ & $\begin{array}{l}\text { Public and } \\
\text { Private High Schools }\end{array}$ \\
\hline Organizations Sampled & 91 & 75 & 59 & 23 & 21 & 4 & 6 \\
\hline Number of Employees/Students in Sample & 6,829 & 10,516 & 17,556 & 16,653 & 42,790 & 41,982 & 39,352 \\
\hline Total Committed Incentive Expense & $\$ 78,224$ & $\$ 83,563$ & $\$ 75,336$ & $\$ 100,420$ & $\$ 75,427$ & $\$ 10,670$ & $\$ 14,832$ \\
\hline Average Incentive Expense per Employee/Student & $\$ 11.45$ & $\$ 7.95$ & $\$ 4.29$ & $\$ 6.03$ & $\$ 1.76$ & $\$ 0.25$ & $\$ 0.38$ \\
\hline Total Committed Subsidy Expense & $\$ 64,300$ & $\$ 76,880$ & $\$ 250,414$ & $\$ 108,543$ & $\$ 230,817$ & $\$ 558,500$ & $\$ 0$ \\
\hline Average Subsidy Expense per Employee/Student & $\$ 9.42$ & $\$ 7.31$ & $\$ 14.26$ & $\$ 6.52$ & $\$ 5.39$ & $\$ 13.30$ & $\$ 0.00$ \\
\hline Total Committed Activity Expense & $\$ 15,003$ & $\$ 17,985$ & $\$ 19,148$ & $\$ 8,535$ & $\$ 15,775$ & $\$ 2,860$ & $\$ 1,110$ \\
\hline Average Activity Expense per Employee/Student & $\$ 2.20$ & $\$ 1.71$ & $\$ 1.09$ & $\$ 0.51$ & $\$ 0.37$ & $\$ 0.07$ & $\$ 0.03$ \\
\hline Total Committed Other Expense & $\$ 450$ & $\$ 0$ & $\$ 1,860$ & $\$ 0$ & $\$ 4,200$ & $\$ 136,000$ & 0 \\
\hline Average Other Expense per employee/student & $\$ 0.07$ & $\$ 0.00$ & $\$ 0.11$ & $\$ 0.00$ & $\$ 0.10$ & $\$ 3.24$ & $\$ 0.00$ \\
\hline
\end{tabular}

Source: Maricopa County Trip Reduction Program, Committed Expense Analysis of Participating Organizations, August 2005, p.4 [1].

Organizations were asked not to include labor costs in the committed expenses on the trip reduction plan. Categories selected for committed expenses:

- Incentives (drawings, prizes to encourage alternate mode usage, point program...)

- Subsidies (bus, carpool...)

- Trip reduction plan activities (High Pollution Advisory with employer prizes, bike week...)

- Other TRP Expenses (campus shuttles, inter-company transit...) 
Table 2 - Average Annual Budgeted Expense per Employee by Employer Type

\begin{tabular}{|c|c|}
\hline Group & $\begin{array}{c}\text { Average Budgeted Expense } \\
\text { per Employee }\end{array}$ \\
\hline Landscaping & $\$ 1.39$ \\
\hline Food Retail & $\$ 1.66$ \\
\hline Schools (K-12 ${ }^{\text {th }}$ Grade) & $\$ 2.63$ \\
\hline Post-High School Education & $\$ 3.36$ \\
\hline Products - Retail & $\$ 3.55$ \\
\hline Food Products & $\$ 4.91$ \\
\hline Health-Related Services & $\$ 6.31$ \\
\hline Government (City/Town) & $\$ 7.52$ \\
\hline High Technology & $\$ 7.56$ \\
\hline Utility/Phone/Waste Management & $\$ 9.07$ \\
\hline Services - Other & $\$ 9.60$ \\
\hline Home Manufacturing & $\$ 10.13$ \\
\hline Contractors & $\$ 11.20$ \\
\hline Television/Radio & $\$ 11.24$ \\
\hline Truck/Courier/Warehouse & $\$ 11.85$ \\
\hline Health - Other Centers & $\$ 12.73$ \\
\hline Health - Hospital & $\$ 13.62$ \\
\hline Entertainment & $\$ 13.92$ \\
\hline Manufacturing & $\$ 16.67$ \\
\hline Hospitality - Hotels \& Clubs & $\$ 16.97$ \\
\hline Community/Non-Profit & $\$ 18.68$ \\
\hline Products - Wholesale & $\$ 20.53$ \\
\hline Transport Related & $\$ 21.75$ \\
\hline Hospitality - Eateries & $\$ 22.10$ \\
\hline Accounting/Law/Design/Consultants & $\$ 25.87$ \\
\hline Print Services & $\$ 26.65$ \\
\hline Services - Insurance/Brokers & $\$ 27.40$ \\
\hline Auto Related Services \& Sales & $\$ 41.72$ \\
\hline Government (County/state/federal) & $\$ 55.21$ \\
\hline Services - Banks & $\$ 65.75$ \\
\hline
\end{tabular}

Source: Maricopa County Trip Reduction Program, Committed Expense Analysis of Participating Organizations, September 2007, p.7 [4].

Both the federal and California Clean Air Acts require ozone nonattainment areas like the San Joaquin Valley to adopt all reasonable and feasible measures to reduce emissions. The California Health and Safety Code Section authorized and set expectations for the San Joaquin Valley District to implement an employer trip reduction program. District Rule 9410 (EmployerBased Trip Reduction) satisfies a federally-enforceable commitment and is designed to share 
the air pollution clean-up burden traditionally targeted at stationary sources [5]. The 2009 District report on Rule 9410 indicates that cost information was estimated from stakeholders, including employers. These estimations are prospective (forecasted) costs that employers would incur once the rule goes into effect. The report grouped costs into three categories: Initial Startup, Capital, and Recurring. District staff used cost information provided by stakeholders through interviews and voluntary surveys and existing programs, such as their own trip reduction program. District staff actively solicited written and verbal cost data from stakeholders and incorporated responses into the cost-effectiveness analysis. Costeffectiveness was calculated by dividing the annualized cost of a control technique with the annual emission reduction achieved by that technique. The cost-effectiveness is expressed in dollars per ton of pollutants reduced (\$/ton). Table 3 is the "Absolute Cost-Effectiveness" calculated by the District. Tier One worksites have 100-249 eligible employees, and Tier Two have $\mathbf{2 5 0}$ or more eligible employees. Also noted in Table 3 are Tiers One and Two of the Federal Migrant and Seasonal Agricultural Worker Protection Act (MSPA) affecting employers in the Valley subject to this Rule 9410.

Table 3 - District Calculated Absolute Cost-Effectiveness

\begin{tabular}{|l|c|c|c|c|c|}
\hline $\begin{array}{c}\text { Type of } \\
\text { Worksite }\end{array}$ & $\begin{array}{c}\text { Number of } \\
\text { Worksites }\end{array}$ & $\begin{array}{c}\text { Average Annual } \\
\text { Cost/Worksite } \\
\text { until 2014 }\end{array}$ & $\begin{array}{c}\text { Annual Cost for } \\
\text { All Worksites } \\
\mathbf{\$} / \text { ton/yr) }\end{array}$ & $\begin{array}{c}\text { Emissions } \\
\text { Reduction } \\
\text { (tons/yr) }\end{array}$ & $\begin{array}{c}\text { Absolute Cost- } \\
\text { Effectiveness } \\
\text { (\$/ton } \\
\text { reduced) }\end{array}$ \\
\hline Tier One & 1,322 & $\$ 2,310$ & $\$ 3,053,820$ & 220 & $\$ 13,894$ \\
\hline $\begin{array}{l}\text { MSPA } \\
\text { Tier One }\end{array}$ & 20 & $\$ 2,460$ & $\$ 49,200$ & 3 & $\$ 14,796$ \\
\hline Tier Two & 533 & $\$ 3,249$ & $\$ 1,731,717$ & 207 & $\$ 8,375$ \\
\hline $\begin{array}{l}\text { MSPA } \\
\text { Tier Two }\end{array}$ & 8 & $\$ 4,741$ & $\$ 37,928$ & 3 & $\$ 12,221$ \\
\hline Total & 1,883 & $\$ 3,190$ & $\$ 4,872,665$ & 433 & $\$ 11,253$ \\
\hline
\end{tabular}

Annual cost for all worksites $=$ Average annual cost per worksite $\mathrm{x}$ number of worksites. Example for Tier One: $\$ 2,310 /$ worksite x 1,322 worksites $=\$ 3,053,820 /$ year total cost; $\$ 3,053,820 /$ year total cost $\div 220$ ton/year reduction $=\$ 13,894 /$ ton reduced.

Annual cost per worksite was estimated by calculating administrative labor costs. Examples of one-time costs included developing policies and procedures, setting up a guaranteed ride home program, installing an on-site transit information center, soliciting and reviewing proposals, and preparing contracts for setting up on-site vending machines (to reduce off-site trips). Examples of recurring costs included accounting, marketing materials, events, and preparing and administering surveys. The annual average cost per worksite was based on averaged total costs for years 2010 to 2015. Valuable insight will be gained from tracking of how these estimates compare to the realities of applying the employer-based TDM measures and the efficacy of these programs in reducing emissions as projected.

As part of a 2002 research project to explore factors leading to successful, cost-effective employer-based TDM programs, a survey of 49 employers and public agencies and an in-depth focus group discussion were conducted [6]. The research reported that many employers did 
not collect comprehensive data on program costs or could not isolate program costs. Most of the employers surveyed indicated that cost was one of the factors in TDM decisions, but they did not feel confident that they could accurately estimate the costs of their programs.

From the above-cited resources and, specifically, from the best available costs data resource (the CTR database, as discussed in Chapter 3), it is evident that more guidance is needed to collect cost data that would help transportation management associations (TMAs), public agencies that are planning TDM programs, and employers prepare implementation plans for various TDM elements. Developing a database that links TDM costs to impacts also would help with benchmarking, setting goals, and measuring effectiveness of these programs.

\section{How Are TDM Program Benefits Estimated?}

The 1999 "Commuter Assistance Program (CAP) Evaluation Manual" was developed by CUTR for FDOT to assist Florida's CAPs in their efforts to measure and evaluate their performance. The manual focuses on providing the information necessary for a CAP to devise and conduct its own evaluation program [7]. It also provided guidance on how to report the results of that evaluation so that key CAP funding sources, elected officials, and the general public can understand and appreciate the efforts of the CAP in addressing traffic congestion, air quality, and mobility concerns. With the manual, transit and highway professionals are able to 1 ) understand the concepts of CAP design and how TDM programs can be applied in diverse markets, 2) grasp what is needed to plan, design, implement, operate, and evaluate effective CAP projects successfully, and 3) use the guidance materials and technical tools compiled and developed in this effort for implementing effective CAP projects. Required performance measures are those that the FDOT Central Office mandated all CAP offices in Florida to track and report, on at least an annual basis, including the following:

- Number of commuters requesting assistance

- Number of commuters switching modes

- Number of vans in service (where applicable)

- Number of vehicle trips eliminated

- Vehicle miles eliminated

- Employer contacts

- Parking spots saved/parking needs reduced

- Commuter costs saved

- Major accomplishments

For the purposes of evaluation, the data collection requirements can be divided into two distinct categories: those data elements collected by CAP staff, and those requiring surveys. To compile the information required to evaluate the program, a survey of database members is necessary. District optional performance measures are those that FDOT has determined are appropriate for some of the CAP programs to show progress, including gasoline saved, emissions reduced, information materials distributed, special events, and media/community relations. Other performance measures are those that can help a CAP illustrate the 
effectiveness of its programs in meeting program or regional objectives. These measures were developed to allow a CAP the flexibility to tailor an evaluation program that closely matches program goals and objectives and to measure CAP effects on markets and groups, such as employers and the general public that directly or indirectly are influenced by CAP efforts. Some examples would be percent of employers with TDM programs, commuter costs saved, and percent of employers wanting assistance from the regional CAP.

FDOT has since moved to research better measurements that increase attention on improving performance of CAPs and emphasize the overall State CAP Program impacts.

To assess the effects of campaigns such as "Spare the Air" in California, Schreffler, (2003), developed a simple, low-cost method for quantifying impacts on travel and emissions. The method allowed for program cost-effectiveness to be assessed by dividing annual program costs by annual emission reductions [8]. The method involves the following 10 steps:

1. Create or modify survey and sample size.

2. Conduct field survey during ozone season.

3. Tabulate results.

4. Estimate total number of reducers.

5. Estimate average trip reduction.

6. Apply self-reported trip reduction correction factor.

7. Estimate total adjusted trips reduced.

8. Determine proportion of work and non-work trips reduced.

9. Estimate VMT reduction.

10. Estimate emissions reduction.

The "Spare the Air" campaign program budget for 2000 was approximately $\$ 140,000$. It was found that the program reduced 0.351 tons of NOx per "Spare the Air" day. There were six such days in 2000, for a total of 2.106 tons reduced. Adding all ozone precursors, the total reduction is 4.69 tons over the six days $(2.106+2.22+0.36)$. Cost-effectiveness would be estimated at a total of $\$ 29,850$ per ton reduced, or $\$ 14.93$ per pound.

A 2007 NCTR research study combined two common goals of transportation agencies: reducing traffic congestion and improving the efficiency of the existing transportation system [9]. By monitoring, evaluating, and communicating TDM strategies and their combined impacts on the roadway system in a visual way, planners, traffic operations staff, TDM professionals, decisionmakers, and elected officials can be talking the same language when comparing available costeffective measures to reduce congestion with a focus on performance, not a given solution.

The NCTR study used a micro-simulation traffic model to simulate the effects of Washington State CTR programs implemented by 189 employers in an 8.6-mile segment of I-5 in the Seattle downtown area. The current performance of the selected network with the actual volumes provided by the Washington State DOT (Scenario With TDM) was compared to that of a scenario with vehicle trips actually reduced by CTR programs at the worksites added onto the network (Scenario Without TDM). Performance measures analyzed included the spatial and 
temporal extent of congestion, recurring delay, speed, and travel time. On the segment of I-5 in the study area, the savings in AM peak delay due to CTR programs were 152,489 vehicle minutes, and 17,297 vehicle miles of travel were reduced. Savings in PM peak delay were 169,486 vehicle minutes, and 14,510 vehicle miles were reduced. Fuel saved in the AM and PM peak were 3,489 and 4,314 gallons, respectively.

The project demonstrated that small changes in the location or time could substantially alter transportation system performance. In many areas of the study corridor and/or times of day, TDM made a significant impact on congestion, but not in all areas or times of day. Recognizing that TDM, like every other transportation solution, is not a panacea for every congested segment or period, some TDM advocates may need to manage expectations for TDM's impacts. Future research recommended as the result of that study included:

- Development of national standards for measuring the performance of TDM that integrates with other transportation systems measures.

- Development of cost/benefit analysis of TDM programs to communities and businesses.

- Measurement of the impact of TDM programs on freeways, arterials, and surface streets.

- Analyses of the additive or multiplicative effects of combining different TDM strategies with appropriate ITS applications locally and regionally.

The fourth bullet above (italicized) was the focus of this project. Adding a TDM element to a sketch-planning tool such as IDAS would provide the opportunity to consider TDM strategies among the alternatives weighed based on their cost-effectiveness to resolve an air quality or capacity issue.

In a report published online in January 2010, the authors observed six sites in the MinneapolisSt. Paul Metropolitan Area that had on-site parking, a known number of employees, and TDM strategies in place at the time of observation [10]. Statistical information about the sites and the employer-based TDM programs were collected through interviews with property or transportation managers. Trip generation and parking counts were collected on non-holiday weeks from 7:00 - 9:00 a.m., 11:00 a.m. - 1:00 p.m., and 4:00 - 6:00 p.m. to cover the peak traffic and parking periods. The study concluded that TDM programs reduce traffic generation rates by 27 to 37 percent and parking generation by 11 to 21 percent, depending on the time of day and other variables. Furthermore, the authors recommended a 30 percent reduction in traffic generation and a 10 percent reduction in parking stall requirements (compared with the Institute of Transportation Engineers' standard rates) when conducting traffic impacts analysis for a proposed office building that will implement a TDM program. The authors go on to note that the reduction in traffic generation could often be the difference between deciding to install a \$200,000 traffic signal or extra parking stalls with construction priced at between $\$ 3,000$ and $\$ 4,000$ or a stall in a parking ramp costing between $\$ 15,000$ and $\$ 20,000$.

How Have TDM Benefit/Cost Analyses Been Conducted? 
Another NCTR study (12) developed a model, TRIMMS ${ }^{\odot}$ 2.0, which allows quantifying the net social benefits of a wide range of TDM initiatives in terms of emission reductions, accident reductions, congestion reductions, excess fuel consumption, and adverse global climate change impacts. The model also includes a sensitivity analysis module that provides program cost-effectiveness assessment, which allows conducting a TDM evaluation to meet the CMAQ Improvement Program requirements for program effectiveness assessment and benchmarking.

\section{Notes on Literature Review}

As indicated in the publications cited herein, employer-based TDM programs can reduce drivealone rates, mitigating congestion and improving air quality. Some evaluation of the effects of demand management estimation is possible via modeling, but this work has been done retrospectively rather than predicatively. A sketch-planning tool that interfaces with travel demand models would facilitate the estimation of the impacts of deploying TDM strategies on delay, speed, and travel time through specific corridors. Also, a technique that would help employers and state agencies in preparing budgets to plan expenditures of TDM programs would fill a gap in the field of TDM performance measuring. Such a technique would improve cost-effectiveness analysis and help standardize measures-of-effectiveness (MOEs) of TDM strategies. 
As mentioned in Chapter 1, the overlapping tasks of this and the WSDOT study made it possible to use the CTR survey data from the State of Washington as the primary source of conducting the analysis of the benefit/cost of TDM programs. The benefits (impacts) were measured by developing the Transportation Demand Management Assessment Procedure (TDMAP) as a sketch-planning modeling approach to feed WSDOT's travel model. ${ }^{1}$ TDMAP is a low-cost method to help plan TDM strategies as part of an overall transportation planning process. Ideally, it would be combined with this NCTR project, which focuses on relating the costs, to find the most cost-effective mix of program elements for conditions in a corridor.

The WSDOT project built a procedure to link the TDM model (TRIMMSC 2.0, developed by NCTR/FDOT) with a four-step planning model. The expectation was that this NCTR/FDOT project would help analysts identify and choose the most cost-effective mix of program elements for improving traffic and air quality conditions in a corridor and see how the cost and mix varies with the desired level of change.

TDMAP incorporates TDM into the transportation planning process by modifying mode split tables to reflect the impact of implementing a particular TDM strategy or mix of strategies in specific corridors over time. Under the WSDOT-funded project, the research team developed TDMAP as a sketch-planning modeling approach to incorporate TDM into WSDOT's travel demand model. TDMAP does so by (1) extracting mode split tables from the model; (2) processing them to be compatible with TRIMMSC 2.0, an existing tool that estimates changes in travel behavior as a result of implementing different TDM strategies; (3) running the tables through TRIMMSC 2.0; and (4) processing them back into the four-step model for distribution over the transportation network. The study developed a low-cost method to help WSDOT plan TDM strategies as part of its overall transportation planning process.

The research was centered on the premise that information on the relationship between effectiveness and costs could be found by using the data-rich CTR program in Washington and several other trip reduction programs from other states. CTR contained over 1,000 before/after employer trip reduction plans, 250,000 completed employee surveys, and selfreported employer cost data from hundreds of locations.

TDMAP consists of a set of subroutines that integrate with NCTR/FDOT-developed TRIMMSC 2.0, as shown in Figure 3. The figure also shows the conceptual framework developed by the CUTR research team to accomplish the goals of this and the WSDOT studies. Appendix A provides an illustration of the TDMAP using FSUTMS as an exercise in applying the process that captures mode split before and after TDM programs are applied and incorporate the changes into the four-step travel demand model.

\footnotetext{
${ }^{1}$ This study is not yet finalized and/or published; a draft report was submitted to WSDOT on February 5, 2010.
} 


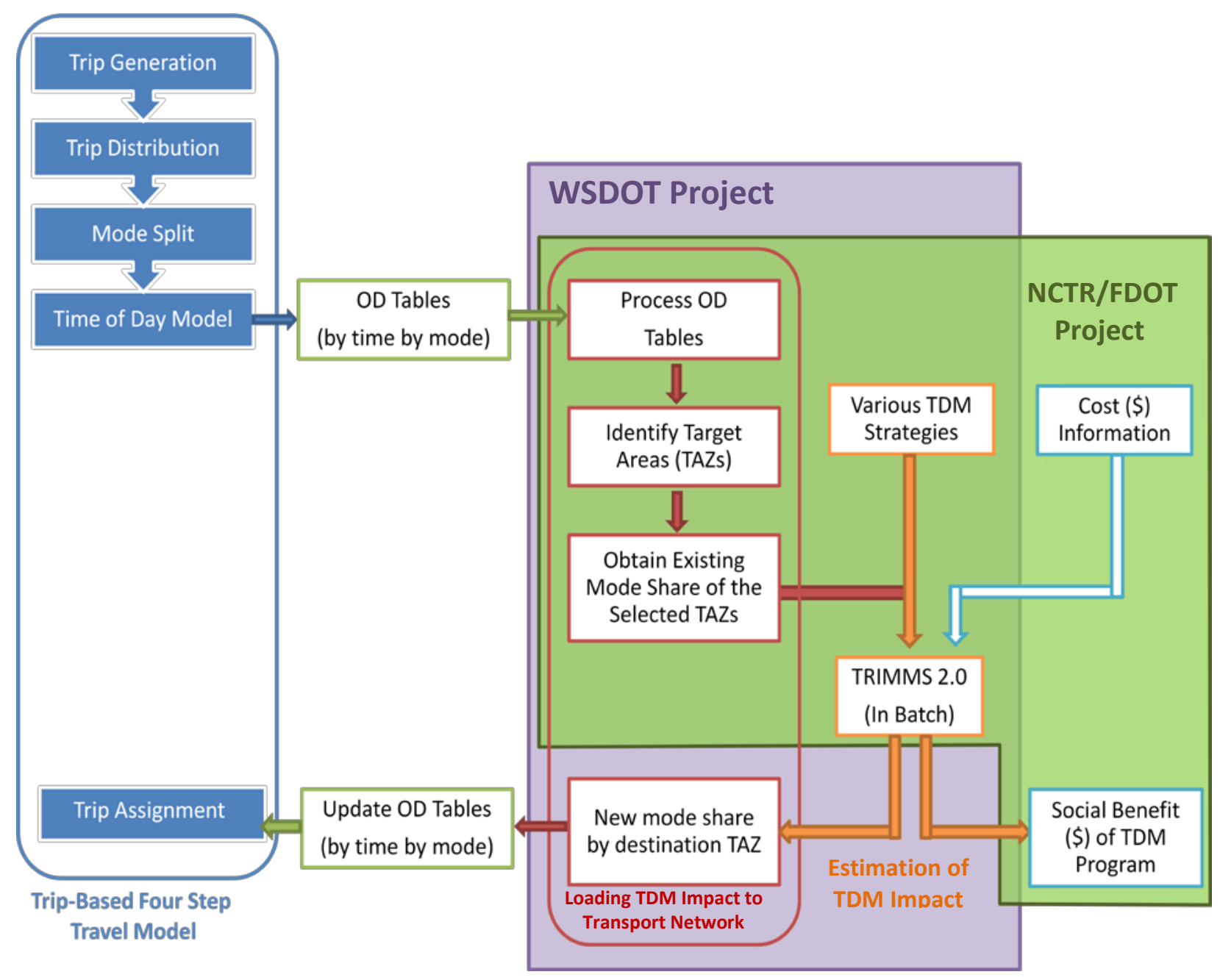

Figure 3 - Conceptual Frameworks for Integrating a B/C TDM Analysis Technique with a Travel Demand Model

As the research team came to discover as part of both projects, missing financial data and limited attention to quality control of the cost data that the WSDOT CTR program collected hindered the potential usefulness of the data. It should be noted that the purpose of the data collection efforts under these trip reduction ordinances differs from what would be ideal for our purposes. In most cases, worksites need only to demonstrate good-faith efforts in reaching set goals. The data collected on expenditures, employer programs, and commuting behavior are intended and designed to support reporting requirements, program administration, and performance monitoring. Research and analysis are secondary purposes in the data collection process.

The CUTR team attempted to build a statistical model that can explain a relationship between various TDM programs, including subsidy and the change of mode share. The effort focused on finding a relationship between the amount of subsidy provided to individuals who use alternate modes and the increase of the subsidized mode shares of commuting. 
Approximately 1,100 worksites participated in the trip reduction program at any one time. The program collected three series of data from each worksite to administer the program and measure its success: how each employer's workforce commutes to work, what employers plan to do to reduce commute vehicle trips to their worksites, and how much each employer spends on reducing trips and complying with the administrative requirements of the program (including developing plans and surveying employees about their commuting.

Approximately 85 percent of employee commute surveys were conducted from Fall of evennumbered years to Summer of odd-numbered years. The remaining surveys were conducted during the remaining 15 months of the two-year cycle. Thus, most of the 2007 employee commuting surveys were collected in Fall 2006 through Summer 2007. The surveys in 2003, 2005, and so forth were collected two, four, etc., years earlier.

The reports of employer plans were collected and used by local jurisdictions that administer the state's trip reduction program. Most jurisdictions required all employers to complete an annual report every year, generally at the end of the calendar year, although the two counties with the most employers, King and Spokane, staggered their reporting schedules throughout the year ${ }^{2}$. A few jurisdictions in King County allowed employers whose employee commuting survey showed that they met the drive-alone or VMT reduction targets (set by the program's enabling legislation) to skip the annual report for the following year. Thus, after the 2007 employee survey, a successful employer might skip the 2007 report. The very earliest employer plan data, from the first two years of the program, exist only in paper form in a variety of different formats and were not coded for use in this analysis. This is an unfortunate limitation, because the largest changes in commuting behavior at many worksites occurred within the first two years of the program.

The 2007 cost (employer expenditure) survey was conducted during the same period that employers were conducting their employee commute surveys, but was scheduled so that the work of completing the survey did not coincide with the work of administering the commute survey. Thus, the 2007 expenditure survey was conducted in Fall 2006-early Spring 2007. It covers costs for late 2005 and early 2006, setting the stage for the behavior captured in the 2007 employee commute survey. The 2005 and 2003 cost surveys were collected on the same schedule, but two and four years earlier, respectively. Cost surveys for 1999 and 2001 were conducted using a different methodology than those for 2003-2007. The data from these cost surveys are available, but not all of the information needed to reconcile them with the 20032007 surveys was readily available. Data from cost surveys earlier than 1999 are available only as aggregates for the entire CTR program, not for individual employers. This, again, is an unfortunate limitation of the data.

Given gaps in the employer annual report/plans (either not submitted by the employer or not entered by WSDOT into the database because of staffing limitations), an attempt was made to

\footnotetext{
${ }^{2}$ The description here covers the way the program collected data through late 2007, which is the period used in this analysis. In 2006, the state legislature revised the program's enabling legislation, and some data collection schedules and practices are expected to change as a result, starting in mid 2008.
} 
match reports to fill the gaps, choosing (1) a report from the year before the one that was missing or (2) the year after, and then dropped from the analysis if neither were available. That is, a 2007 record in the data files that were analyzed would have a 2007 commute survey, a 2007 cost survey, and a 2007 employer plan, if available. If a 2007 plan was not available, a 2006 plan would be used; if that were not available, then the 2008 plan would be used. If neither were available, the record was dropped from the combined linked dataset.

Originally included in the dataset were 870 individual records. This number was reduced to 319 pairs when an attempt was made to calculate the difference between survey cycles. Initial efforts to find a relationship between alone-share and total expense per employee were not successful. As can be seen in Table 4, the result shows rather a mixed trend. Also, it was learned that some data will need to be re-evaluated.

Table 4 - Mode Share Change vs. TDM program Cost per Employee

\begin{tabular}{|c|c|c|c|c|c|}
\hline \multirow[b]{2}{*}{ Business Type } & \multicolumn{4}{|c|}{ Changes between Two Survey Cycles } & \multirow{2}{*}{$\begin{array}{c}\text { \# of } \\
\text { Data } \\
\text { Entries }\end{array}$} \\
\hline & $\begin{array}{c}\text { Drive-Alone } \\
\text { Rate }\end{array}$ & $\begin{array}{l}\text { Adj Sub Cost } \\
\text { Per Employee }\end{array}$ & $\begin{array}{c}\text { Total Exp } \\
\text { Per Employee }\end{array}$ & $\begin{array}{c}\text { No. of } \\
\text { Employees }\end{array}$ & \\
\hline Agriculture & $-0.35 \%$ & $\$ 0.33$ & $\$ 3.81$ & -22.0 & 2 \\
\hline Construction & $1.45 \%$ & $\$ 3.19$ & $\$ 2.79$ & 30.0 & 1 \\
\hline Education & $-0.90 \%$ & $\$ 5.70$ & $\$ 13.37$ & 59.2 & 25 \\
\hline Finance & $-1.61 \%$ & $\$ 11.24$ & $\$ 3.32$ & 24.1 & 33 \\
\hline Government & $-0.01 \%$ & $\$ 5.60$ & $\$ 18.10$ & 4.8 & 63 \\
\hline HealthCare & $-1.24 \%$ & $(\$ 16.10)$ & (\$13.69) & 118.4 & 24 \\
\hline Information Services & $-5.31 \%$ & $(\$ 34.46)$ & $(\$ 44.73)$ & -62.1 & 13 \\
\hline Manufacturing & $-1.56 \%$ & $\$ 17.87$ & $\$ 17.95$ & -20.5 & 55 \\
\hline Military & $-0.83 \%$ & $\$ 1.12$ & $\$ 1.61$ & -50.3 & 3 \\
\hline Other Business & $1.87 \%$ & $\$ 12.78$ & $\$ 10.11$ & -27.6 & 23 \\
\hline Personal Services & $-1.37 \%$ & (\$12.54) & (\$32.57) & -2.4 & 38 \\
\hline Public Utilities & $-13.55 \%$ & $\$ 4.12$ & $\$ 0.82$ & 34.0 & 2 \\
\hline Retail Trade & $1.08 \%$ & $\$ 1.16$ & $\$ 3.23$ & -43.3 & 14 \\
\hline Transportation & $0.44 \%$ & $\$ 1.18$ & $\$ 3.39$ & 23.8 & 12 \\
\hline$\#$ N/A & $0.60 \%$ & $(\$ 0.06)$ & $\$ 3.00$ & -37.5 & 11 \\
\hline Grand Total & $-0.85 \%$ & $\$ 2.75$ & $\$ 2.48$ & 6.0 & 2 \\
\hline
\end{tabular}

Several rounds of efforts were made to clean up the data by removing outliers and almostcertain misreported data. After data filtering, the size of dataset was reduced to 275 pairs. An advanced data mining technique called GUIDE (Generalized, Unbiased, Interaction Detection and Estimation) was adopted to analyze the data. GUIDE is a hybrid tree algorithm that can split the data and fit a model. The main idea behind GUIDE is the use of a piecewise simple linear regression model to approximate the true model. This has two important advantages in terms of model interpretation. First, because only one independent variable is employed in each piece of the model, there is no difficulty or ambiguity in understanding the parameter estimates. 
Second, by using a recursive partitioning algorithm to construct the pieces, the model can be represented as a binary decision tree in which the splits take the form $X \leq c$, if $X$ is an ordered variable, or $\mathrm{X} \in \mathrm{S}$, if $\mathrm{X}$ is nominal. However, it was still not feasible to uncover a statistical significance of subsidy reducing the drive-alone share. In addition, it was noted that many employers in the cost dataset had participated in the CTR program before 2001, which means mode share in the cost survey dataset does not include baseline mode share of the company. This actually incurs another concern that relationships uncovered by the dataset could be biased, because the impact of subsidy at the beginning of the TDM program should be different from the continuous stage of program.

In reference to the site's baseline survey, BA is a worksite's first survey in the CTR program. It is supposed to be done before the program starts (or makes any changes to its established program). Two years later, the site does its first survey to measure progress against its baseline. This is its first goal, or G1 survey. Two years after that (4 years after the baseline) the site does its second survey to measure progress against its baseline. This is its second goal, or G2 survey. Six years after the baseline is $G 3,8$ years after is $G 4 A$, and 10 years after is G4B, etc.

Table 5 As can be seen in Table 5, if a company joined the CTR program in 1993, any subsidy information in the cost dataset (which was available only for 2003, 2005, and 2007) becomes very difficult to interpret unless additional information regarding subsides for the previous year is obtained.

In reference to the site's baseline survey, BA is a worksite's first survey in the CTR program. It is supposed to be done before the program starts (or makes any changes to its established program). Two years later, the site does its first survey to measure progress against its baseline. This is its first goal, or G1 survey. Two years after that (4 years after the baseline) the site does its second survey to measure progress against its baseline. This is its second goal, or G2 survey. Six years after the baseline is $G 3,8$ years after is $G 4 A$, and 10 years after is $G 4 B$, etc.

Table 5 - Example of Cost Data and Program Data

\begin{tabular}{|c|c|c|c|c|c|c|c|c|c|c|}
\hline $\begin{array}{c}\text { Survey } \\
\text { Type }\end{array}$ & Cycle & $\begin{array}{c}\text { Cww- } \\
\text { Share }\end{array}$ & $\begin{array}{c}\text { Alone- } \\
\text { Share }\end{array}$ & $\begin{array}{c}\text { Carpool- } \\
\text { Share }\end{array}$ & $\begin{array}{c}\text { Vanpool- } \\
\text { Share }\end{array}$ & $\begin{array}{c}\text { Bus- } \\
\text { Share }\end{array}$ & $\begin{array}{c}\text { Walk- } \\
\text { Share }\end{array}$ & $\begin{array}{c}\text { Bike- } \\
\text { Share }\end{array}$ & $\begin{array}{c}\text { Tele- } \\
\text { Share }\end{array}$ & $\begin{array}{c}\text { Other- } \\
\text { Share }\end{array}$ \\
\hline BA & 1993 & $1 \%$ & $90 \%$ & $8 \%$ & $0 \%$ & $0 \%$ & $0 \%$ & $1 \%$ & $0 \%$ & $1 \%$ \\
\hline G1 & 1995 & $6 \%$ & $74 \%$ & $18 \%$ & $0 \%$ & $0 \%$ & $1 \%$ & $1 \%$ & $0 \%$ & $1 \%$ \\
\hline G2 & 1997 & $3 \%$ & $78 \%$ & $16 \%$ & $0 \%$ & $1 \%$ & $0 \%$ & $1 \%$ & $0 \%$ & $1 \%$ \\
\hline G3 & 1999 & $3 \%$ & $75 \%$ & $18 \%$ & $0 \%$ & $1 \%$ & $0 \%$ & $1 \%$ & $0 \%$ & $1 \%$ \\
\hline G4A & 2001 & $12 \%$ & $76 \%$ & $10 \%$ & $0 \%$ & $0 \%$ & $0 \%$ & $0 \%$ & $1 \%$ & $0 \%$ \\
\hline G4B & 2003 & $3 \%$ & $86 \%$ & $8 \%$ & $0 \%$ & $1 \%$ & $0 \%$ & $1 \%$ & $0 \%$ & $0 \%$ \\
\hline G4C & 2005 & $9 \%$ & $81 \%$ & $9 \%$ & $0 \%$ & $1 \%$ & $0 \%$ & $1 \%$ & $0 \%$ & $0 \%$ \\
\hline G4D & 2007 & $12 \%$ & $77 \%$ & $10 \%$ & $0 \%$ & $0 \%$ & $0 \%$ & $0 \%$ & $0 \%$ & $0 \%$ \\
\hline
\end{tabular}


Therefore, it was decided to use employers that have baseline survey $B A$, and CTR Program survey data were selected and analyzed. A total of 338 employers were indentified that joined the CTR program in 1993 and completed all surveys.

Table 6 represents the number of employers that joined the CTR program by year and by survey cycles.

Table 6 - Number of Participating Employers by Survey Cycle and Starting Year of Program

\begin{tabular}{|c|c|c|c|c|c|c|c|c|c|}
\hline Year & BA & G1 & G2 & G3 & G4A & G4B & G4C & G4D & $\begin{array}{l}\text { Grand } \\
\text { Total }\end{array}$ \\
\hline 1993 & 761. & & & & & & & & 761 \\
\hline 1995 & 47 & & & & & & & & 818 \\
\hline 1997 & 181 & & 702 & & & & & & 969 \\
\hline 1999 & 121 & & 61 & 653 & & & & & 960 \\
\hline 2001 & 134 & & 100 & & 593 & 2 & & & 1,036 \\
\hline 2003 & 104 & & 123 & 8.6 & 53 & 55.5 & 2 & & 1,051 \\
\hline 2005 & 112 & & 110 & 9.8 & 73 & 46 & 507 & 5 & 1,056 \\
\hline 2007 & 94 & 91 & 76 & 78 & 78 & 63 & 35 & 451 & 966 \\
\hline $\begin{array}{c}\text { Companies } \\
\text { Staying in CTR }\end{array}$ & & 72 & 58 & 54 & 45 & 49 & 12 & 338 & \\
\hline Grand Total & 1,554 & 1,457 & 1,172 & 971 & 797 & 666 & 544 & 456 & 7,617 \\
\hline
\end{tabular}

Further analysis of the data of 338 employers revealed that a significant reduction of their DA (Drive-Alone) mode share change occurred in the first two survey cycles and tends to flatten out during the rest of survey cycle, although the number of companies offering certain types of subsidy for alternate mode has been continuously increasing.

To verify the significance of alone-share changes in the first two survey cycles, all CTR surveys were rearranged based on the starting year of the program and plotted with a survey cycle. As can be seen in Error! Reference source not found., the larger amount of reduction on aloneshare occurs between surveys BA and "G1", regardless of the program start year. 


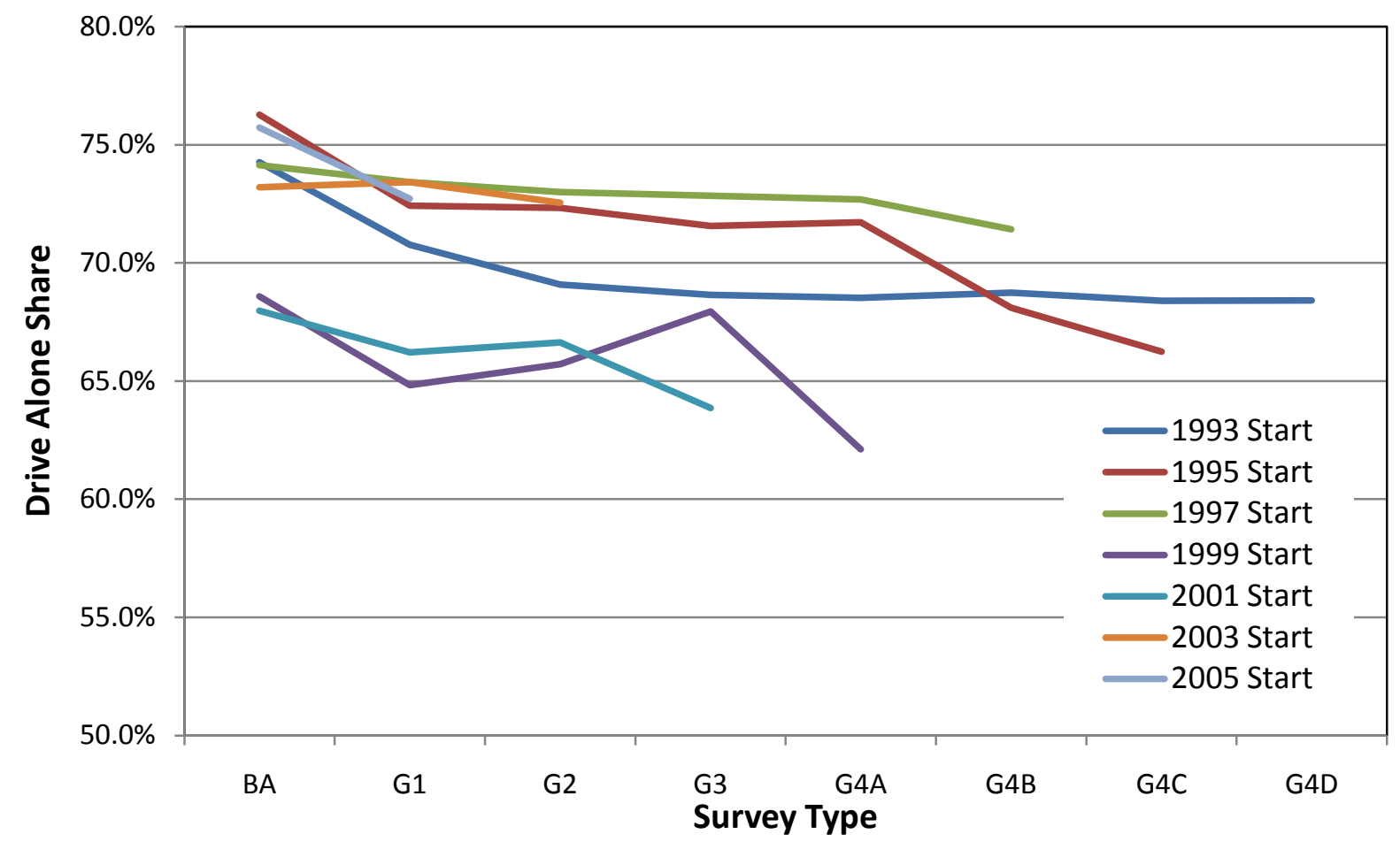

Figure 4 - Drive-Alone Mode Share Change by Program Start Year

Table 7 shows the drive-alone mode share changes between surveys cycles.

Table 7 - Drive-Alone Mode Share Changes between Survey Cycles

\begin{tabular}{|l|c|c|c|c|c|c|c|}
\hline & 1993 Start & 1995 Start & 1997 Start & 1999 Start & 2001 Start & 2003 Start & 2005 Start \\
\hline BA-G1 & $-3.5 \%$ & $-3.9 \%$ & $-0.7 \%$ & $-3.7 \%$ & $-1.8 \%$ & $0.2 \%$ & $-3.0 \%$ \\
\hline G1-G2 & $-1.7 \%$ & $-0.1 \%$ & $-0.4 \%$ & $0.9 \%$ & $0.4 \%$ & $-0.9 \%$ & \\
\hline G2-G3 & $-0.4 \%$ & $-0.8 \%$ & $-0.2 \%$ & $2.2 \%$ & $-2.8 \%$ & & \\
\hline G3-G4A & $-0.1 \%$ & $0.2 \%$ & $-0.1 \%$ & $-5.8 \%$ & & & \\
\hline G4A-G4B & $0.2 \%$ & $-3.6 \%$ & $-1.3 \%$ & & & & \\
\hline G4B-G4C & $-0.3 \%$ & $-1.9 \%$ & & & & & \\
\hline G4C-G4D & $0.0 \%$ & & & & & & \\
\hline
\end{tabular}


The group of sites that started in 1997 is unusual for having such a low reduction in its drivealone rate in its first two years, compared to other groups, and a larger reduction in later years. Our analysis of the data did not indicate any clear reason for this difference. There are five subsidy programs in CTR as follows:
1. Transit Subsidy
2. Carpool Subsidy
3. Vanpool Subsidy
4. Bike Subsidy
5. Walking Subsidy

Each employer offers a different combination of subsidy programs. . 
Table 8 shows the number of subsidy programs offered by employers. For example, the G1 survey shows that 190 employers did not offer any subsidy programs, while 11 employers offered all five subsidy programs. Most employers offered more subsidy programs as time progressed.

Table 9 shows the average of subsidy amount offered to employees by mode. As can be seen in the table, the amount has continuously increased; specifically, the subsidy for the NonMotorized mode has increased almost 8 times between G1 and G4D.

Table 10 shows the mode share change during eight survey cycles. As can be seen in the table, the Drive-Alone rate became flat after the first three cycles. Interestingly, Carpool mode share has decreased over the years, while other modes, such Bus and Bike, increased slowly. Walk mode share has stayed almost the same from the beginning of the program. 
Table 8 - Number of Subsidy Programs by Employer and Survey Cycle

\begin{tabular}{|c|c|c|c|c|c|c|c|c|}
\hline \multirow{2}{*}{$\begin{array}{c}\text { Survey } \\
\text { Cycle }\end{array}$} & \multicolumn{7}{|c|}{ \# of Subsidy Programs Offered by Employer } & NA \\
\hline BA & & 1 & 2 & 3 & 4 & 5 & 338 & 338 \\
\hline G1 & 190 & 75 & 36 & 9 & 4 & 11 & 13 & 338 \\
\hline G2 & 184 & 55 & 44 & 25 & 10 & 12 & 8 & 338 \\
\hline G3 & 125 & 58 & 70 & 27 & 6 & 42 & 10 & 338 \\
\hline G4A & 92 & 52 & 75 & 33 & 10 & 62 & 14 & 338 \\
\hline G4B & 81 & 47 & 79 & 29 & 11 & 83 & 8 & 338 \\
\hline G4C & 69 & 44 & 67 & 34 & 16 & 82 & 26 & 338 \\
\hline G4D & 24 & 36 & 67 & 28 & 25 & 69 & 89 & 338 \\
\hline
\end{tabular}

Table 9 - Average Subsidy (\$) by Survey Cycle

\begin{tabular}{|c|c|c|c|c|c|}
\hline Survey Cycle & $\begin{array}{c}\text { Transit } \\
\text { Subsidy }\end{array}$ & $\begin{array}{c}\text { Carpool } \\
\text { Subsidy }\end{array}$ & $\begin{array}{c}\text { Vanpool } \\
\text { Subsidy }\end{array}$ & $\begin{array}{c}\text { Bike } \\
\text { Subsidy }\end{array}$ & $\begin{array}{c}\text { Walking } \\
\text { Subsidy }\end{array}$ \\
\hline G1 & 19.09 & 4.36 & 13.98 & 2.04 & 1.83 \\
\hline G2 & 19.86 & 6.64 & 23.91 & 7.53 & 1.35 \\
\hline G3 & 27.83 & 9.13 & 21.22 & 4.82 & 4.74 \\
\hline G4A & 30.17 & 13.27 & 26.12 & 8.25 & 7.59 \\
\hline G4B & 37.11 & 14.83 & 33.09 & 11.40 & 10.47 \\
\hline G4C & 38.57 & 17.38 & 36.75 & 12.06 & 11.80 \\
\hline G4D & 38.71 & 23.83 & 43.64 & 17.28 & 15.75 \\
\hline
\end{tabular}

Table 10 - Mode Share by Survey Cycle

\begin{tabular}{|c|c|c|c|c|c|c|c|}
\hline $\begin{array}{c}\text { Survey } \\
\text { Cycle }\end{array}$ & $\begin{array}{c}\text { Drive } \\
\text { Alone }\end{array}$ & Carpool & Vanpool & Bus & Walk & Bike & Telework \\
\hline BA & $74.3 \%$ & $11.5 \%$ & $0.5 \%$ & $7.5 \%$ & $1.9 \%$ & $0.8 \%$ & $0.1 \%$ \\
\hline G1 & $70.8 \%$ & $13.9 \%$ & $0.8 \%$ & $7.9 \%$ & $1.9 \%$ & $0.9 \%$ & $0.2 \%$ \\
\hline G2 & $69.1 \%$ & $14.2 \%$ & $0.9 \%$ & $8.5 \%$ & $2.0 \%$ & $0.9 \%$ & $0.4 \%$ \\
\hline G3 & $68.7 \%$ & $13.7 \%$ & $1.0 \%$ & $8.9 \%$ & $2.0 \%$ & $1.0 \%$ & $0.5 \%$ \\
\hline G4A & $68.5 \%$ & $13.1 \%$ & $1.2 \%$ & $9.5 \%$ & $1.9 \%$ & $0.9 \%$ & $0.6 \%$ \\
\hline G4B & $68.7 \%$ & $12.7 \%$ & $1.3 \%$ & $9.3 \%$ & $2.0 \%$ & $0.9 \%$ & $0.7 \%$ \\
\hline G4C & $68.4 \%$ & $12.4 \%$ & $1.4 \%$ & $9.3 \%$ & $1.9 \%$ & $1.1 \%$ & $0.8 \%$ \\
\hline G4D & $68.4 \%$ & $11.2 \%$ & $1.4 \%$ & $9.7 \%$ & $2.0 \%$ & $1.2 \%$ & $1.1 \%$ \\
\hline
\end{tabular}


While the CTR Cost Survey was intended solely to report the total costs that employers incurred in complying with the CTR program, the survey has the potential for revealing which strategies are the most cost-effective when combined with an assessment of effectiveness (Appendix B). The following summarizes the insights gleaned from working with the data. Most of these insights apply to all the cost surveys reviewed and are not unique to the State of Washington.

Even with a revised survey instrument, there would still be tradeoffs to be considered and limits to what could be done with the data. Without significant incentives for participation, the needs of the analysts or planners are likely to outstrip the willingness of the employers to voluntarily provide the data. Washington follows a quota-sampling strategy for collecting employer cost data. The survey seeks to get responses that cover 40 percent of the public and private worksites and employees in the program in each county, and it re-contacts nonrespondents for each quota until the quota is met. This strategy obtains survey responses from some employers every time the survey is administered. Other employers respond in some years but not others, while others never respond. The Washington program is moving toward seeking this information from all employers every year or two, but it has not yet been implemented. On the other hand, Maricopa County samples employers randomly. Rotating samples from year to year loses some of the explanatory power that a cost census survey or a panel might provide.

In addition, while the surveying agencies did provide guidance and technical assistance on how employers should collect the data, those same agencies fell short on quality control (as discussed in the following section). This shortfall is likely a function of available resources rather than a lack of interest in data quality. Knowing which TDM strategies at the worksite are the most cost-effective could influence how public funds are allocated in support of those private expenditures in those strategies. Therefore, modest attention to data quality, including comparison across time, could prove to be a very low-cost investment. Coupled with providing incentives to employers to provide data, this could improve the coverage and the accuracy of data collected.

The use of incentives for participation by employers may prove invaluable in improving the quality. Part of the challenge for employers is the likelihood that the total trip reduction effort may be not a "cost center" for the employer. Therefore, costs may be spread among a variety of departments or centralized in one location for multiple worksites. Those responsible for completing the forms may not have easy access to the information. For example, the Employee Transportation Coordinator (ETC) for a branch facility may depend on invoices for transit vouchers or vanpool fares paid by headquarters in another state. The use of incentives may help create these "cost centers" for reporting purposes. 
The following section uses the exact wording from the CTR Cost Survey as an example of the issues uncovered during the review. Again, this is not meant as a criticism of what that program does in collecting cost data, because the survey is administered to meet a statutory requirement, rather than to enable research and analysis of the program and its impacts.

1 Which organization or worksite(s) are you reporting on in this survey? (If you administer the CTR Program at more than one worksite you can combine the costs and report them all on this form. Just make sure to list all worksites you are reporting for in the space provided below.)

Most of the surveys for collecting data on employer costs and program elements classify employers by industry type, most commonly based on the North American Industry Classification System (successor to the older Standard Industry Classification System). While these classifications capture some characteristics related to commuting, these surveys may be missing other factors that better relate to commuting opportunities and constraints. Issues such as organizational culture (e.g., is it a manufacturing plant or a public agency where employees are expected to arrive and leave on precise schedules, or is it a private creative or software firm where employees keep individual hours?) and workforce distribution (e.g., office workers vs. factory workers) are likely to explain more of the impact than standard industry classification. A headquarters facility for a manufacturing firm is likely to have more flexibility in commuting hours and more opportunity for telework than a manufacturing site under its control, but both would be classified as manufacturing.

We are asking the next three questions in order to help us contact you in case we need further clarification with your responses. This survey is completely confidential and this information will not be reported to anyone outside of the CTR survey staff.

2 What is your name?

3 What is your Area Code and phone number?

4 What is your email address?

5 What is today's date?

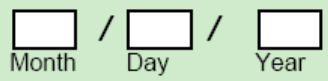

This question illustrates balancing the need to identify individual employers long enough for quality control of the data collection process against employer privacy. It was recognized that employers may not be forthcoming related to investments or overly concerned about accuracy as they seek to maintain their competitive advantage. Protecting the confidentiality of the responses is a given, but additional insight may be gained by linking cost data with other data for the employer or lost if analysis is limited to anonymous case studies. 
The next two questions ask for the start and end date of your CTR program Cost Period. This is the 12-month period in which you will be estimating your organization's Total Yearly Costs in the table on the next page. It would be most helpful to us if you can report for the period of July 1, 2005 through June 30, 2006. However, some organizations may find it easier to report for a different 12-month period.

6 What is the start of your Cost Period?

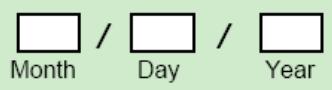

7 What is the end of your Cost Period?

$$
\underset{\text { Month }}{\square} / \square_{\text {Day }} / \square_{\text {Year }}
$$

While facilitating the ease in reporting by allowing employers to align their financial reporting with their fiscal year, the employer's trip reduction plans may be on another schedule. In Washington, costs collected for the alternative reporting periods may not accurately reflect the plans that were in place when the surveys were conducted. A complete description of the data submission schedule appears later in the previous chapter of this report.

8 For each activity in the table below, please tell us how much cost your organization has incurred for supporting and overseeing your CTR program during the 12-month cost period you have described on the previous page. Please give us an estimate of monetary costs, in-kind costs and an estimate total cost for the year.

Monetary Cost Estimate: We are asking about the value of goods and services that your organization contributed in order to administer the CTR Program. Examples of this type of cost include your organization's staff time spent administering the CTR Program and any dues paid to local Transportation Management Associations (TMAs).

In-Kind Cost Estimate: This is the value of goods and services contributed from sources outside your organization. However, please don't include contributions from local governments or transit agencies. We already have this information from the local governments and transit agencies. Examples of this type of cost include donated gift certificates, staff time from local bike shops for workshops held at your organization, and any donated merchandise.

\begin{tabular}{|c|c|c|c|}
\hline Type of Activity & $\begin{array}{l}\text { Monetary Cost } \\
\text { Estimate }\end{array}$ & $\begin{array}{l}\text { In-Kind Cost } \\
\text { Estimate }\end{array}$ & $\begin{array}{l}\text { Total Yearly Cost } \\
\text { Estimate }\end{array}$ \\
\hline \multicolumn{4}{|l|}{$\begin{array}{l}\text { Promoting the CTR Program to employees } \\
\text { (Including ETC time, supplies, etc.) }\end{array}$} \\
\hline \multicolumn{4}{|l|}{$\begin{array}{l}\text { Helping employees with transportation } \\
\text { questions, such as transit schedules, } \\
\text { arranging carpools and vanpools }\end{array}$} \\
\hline \multicolumn{4}{|l|}{$\begin{array}{l}\text { Providing transportation services to } \\
\text { employees, such as guaranteed ride home, } \\
\text { shuttle bus, etc. }\end{array}$} \\
\hline \multicolumn{4}{|l|}{$\begin{array}{l}\text { Financial incentives and subsidies paid } \\
\text { to employees. }\end{array}$} \\
\hline $\begin{array}{l}\text { Facilities such as bike racks, bus shelters } \\
\text { lockers, etc. (including current expenses } \\
\text { only.) }\end{array}$ & & & \\
\hline \multicolumn{4}{|l|}{$\begin{array}{l}\text { Program overhead (time spent processing } \\
\text { incentive payments, in meetings, } \\
\text { conducting surveys, completing annual } \\
\text { reports, etc.) }\end{array}$} \\
\hline $\begin{array}{l}\text { Any other costs that are not covered in } \\
\text { the categories above (please describe in } \\
\text { in question } 9 \text { below) }\end{array}$ & & & \\
\hline
\end{tabular}


Minimizing the effort required of an ETC or employer to provide the data has some drawbacks. Isolating the effects of various program elements is complicated by combining them. For example, the survey combines transportation services such as shuttle bus and emergency ride home programs into a single line-item. Although an analysis of the data can cross-reference the data from the cost survey against data from employer plans to determine whether the employer offered only a shuttle bus, only an emergency ride home, or both, there is no opportunity to estimate the separate expenditure for each elements, when an employer offers both. This limits the ability to estimate the cost of individual elements for analysis or use in a sketch-planning tool. On the other hand, asking costs for each item separately might be more burdensome for the employer, and the person completing the survey might not have the information needed to report separate costs for each individual elements.

A particularly difficult problem arises with asking an ETC to separate the amount of time he/she or other staff spends on different activities (e.g., helping employees with questions, conducting surveys, and helping to administer a financial incentives program). A number of employers reported zero expenditure for trip-reduction services, even though the employer completed and submitted program plans and employee commute surveys and reported ETC time on the program plans (which ask for the number of hours the ETC spends per week). It might be more accurate overall to ask the employer to exclude the ETC's salary from the cost survey, and for analysts to estimate it using an average salary and the number of hours reported on the annual report.

The format of the cost survey mixes capital expenditures (for facilities such as bike racks, bus shelters, and lockers) with recurring operating expenses for dues, informational media, and financial incentives. Taking a one-year snapshot of costs ignores previous expenditures on facilities that may be contributing to current trip reduction choices by employees. On the other hand, asking the employer or ETC to maintain a history of when facilities were installed and to allocate previous capital expenditures over later years would be a burden to the employer.

In summary, the balancing act between the primary purpose of the cost survey, the ease of completion, and needs of analysis to support better decisions about TDM sometimes can yield a data collection system that fails to achieve all of these goals well. However, opportunities exist to improve the way data are collected, to simultaneously reduce the reporting burden and improve the consistency and quality of the data. For example, the Washington program has moved to collect all of its employer plan data and cost/expenditure data through online forms. It also is considering merging the forms to collect cost data at the same time that it collects plan data. These changes offer the potential do to the following:

- Store data from previous years and compare new submissions with old ones to identify changes and ask for descriptions of what happened and why or to prompt the jurisdictions who review the plans to ask about the changes. This could improve consistency and quality of data and make it clear that when a program element disappears from an employer's data, the employer did drop the program rather than forget to report it. 
- Clarify the treatment of time and other units of measure reported in the plans. Some employers have described incentive programs in the program element data as monthly limits on the amount of the incentive. Others have done so by providing the amount of payment made per day. It is not always possible to determine after the fact which kind of description has been provided. An electronic collection system can guide the description to make sure it is clear.

- Use data from the employer plan section of the form to tailor what is asked about expenditures. For example, if past and current plan data indicate no provision of financial incentives, it may be possible to skip questions about how much is spent on such incentives. Or an ETC who reports working five hours per week on trip reduction might be asked to allocate those hours to different categories of activity, consistent with the rest of the cost survey questions.

The examination of the data during the course of this project revealed the importance of quality control, including identifying substantial changes in program offerings and/or expenses. The opportunities for timely review and cleanup of data often are limited. For example, worksites, particularly small ones, enter and leave the Washington program after only a few years (because they become too small to be required to participate). In addition, the position of ETC at many worksites is entry-level and subject to high rates of turnover, which means that the person who reports data in one year may be different from the person who reported it the previous year. 
This project attempted to explain the linkage between performance of TDM at the worksite level and private expenditures in those programs and use this information as inputs to other models to help forecast costs/benefits of TDM. It was found that the data - arguably the best available data of its type anywhere - was insufficient to more fully explain the variance in performance indicators.

There are several plausible explanations why the data were unable to explain much of the change in mode share. Though the data were the best available, several areas were identified related to data quality. Second, an examination of the data found that the steepest drops in single occupant vehicle share occurred within the first couple of plan cycles - 1993-1995 for many of the plans. It is this period that could best explain which program elements contributed to changes in behavior. Unfortunately, the employer expenditure data available for analysis were not collected until 2003, after most of the worksites had achieved their largest reductions in vehicle trips. Another explanation is the most cost-effective solutions may not be the most acceptable to employers and commuters. For example, charging for parking has continually demonstrated the largest immediate impact on mode behavior change. Thus, employers may not have been seeking the most cost-effective solutions and need only show good faith efforts toward reaching their SOV target.

Finally, it was concluded that other factors may be more significant in explaining the change than previously believed. Other research found that the effectiveness of worksite trip reduction programs sometimes depends on organizational culture, composition, and access. Hendricks (2005) found evidence that management support and an effective ETC are not necessary for a successful worksite trip reduction program under some conditions, such as a worksite located in an area with access to high-quality public transportation that employs lower-income staff who must choose transportation cost savings over time savings and convenience [12]. However, she also found that management support and an effective ETC are necessary for a worksite trip reduction program that is successful in reducing its vehicle trip rate if the worksite is not located in an area with access to high-quality public transportation.

The research team concludes that the collection of data on the effectiveness of employer trip reduction programs should be expanded to include corporate culture indicators such as ETC's experience, support, and level of effort. Future surveys should be designed to capture a description of employment composition and include measures to gauge access to high-quality transit and sidewalks/bike paths. In addition to the recommendations made earlier about revisions to the collection of employer cost data, similar recommendations can apply to measuring the cost-effectiveness of commuter assistance programs. These TDM programs do not have an accepted standard practice for measuring performance or quantifying costs like transit systems. Transit systems have the National Transit Database (NTD) of the Federal Transit Administration (FTA) that allows for benchmarking performance over time and among peers. 
In recognition of this gap of public sector TDM programs, FDOT has authorized NCTR to undertake "Project UCARE: Uniform Cost Accounting and Reporting Elements for Transportation Demand Management Programs" in 2010 to help design the database and pilot test the gathering of such data on public sector TDM programs. Project UCARE will involve key stakeholders such as state DOTs, commuter assistance programs, and MPOs in the development of a voluntary data collection system. The focus will include establishing by consensus standard terms and data definitions, key performance outputs and outcome measures, and financial categories. This project should help close the substantial gap at the local, state, and federal levels about other modes (e.g., performance data for carpools and private vanpools are not reported under NTD) and strategies that reduce vehicle trips and vehicle miles of travel (e.g., telework). Much like NTD, this TDM database could be the primary source of comparative TDM information for breakthrough improvements and help inform the allocation of funding based on performance.

In addition, Florida's CAP evaluation will begin to collect performance data using a common methodology that should help analyses like this in the future. 
[1] Comsis Corporation and the Institute of Transportation Engineers in association with the Georgia Institute of Technology (1994), "Overview of Travel Demand Management Measures," Federal Highway Administration, U.S. Department of Transportation. Accessed February 2010 at http://ntl.bts.gov/DOCS/273.html

[2] Center for Urban Transportation Research (1994), "Moving People in Florida: Transit, TDM and Congestion." State Transportation Policy Initiative.

[3] Ernst \& Young (1992), "Regulation XV Cost Survey," South Coast Air Quality Management District.

[4] Maricopa County Trip Reduction Program - Committed Expense Analysis of Participating Organizations (August 2005). Accessed February 2010 at http://maricopa.gov/aq/divisions/trip reduction/docs/pdf/Cost2005.pdf

[5] Maricopa County Trip Reduction Program, Committed Expense Analysis of Participating Organizations (September 2007). Accessed February 2010 at http://www.maricopa.gov/aq/divisions/trip reduction/docs/pdf/Cost2007.pdf

[6] Jessica Hafer Fierro and Nichole Corless (2009), "Rule 9410, Employer Based Trip Reduction," San Joaquin Valley Unified Air Pollution Control District. Accessed Feb. 2010 at http://www.valleyair.org/Workshops/postings/2009/12-1709 9410/Final\%20Draft\%20Staff\%20Report\%20R9410\%20with\%20Appendices.pdf

[7] Comsis Corporation (2002), "Cost-Effectiveness of Transportation Demand Management (TDM) Strategies," Transit Cooperative Research Program Web Document 22 (Project B-4), Transportation Research Board. Accessed February 2010 at http://onlinepubs.trb.org/onlinepubs/tcrp/tcrp webdoc 22-e.pdf

[8] Center for Urban Transportation Research, University of South Florida (1999), "Commuter Assistance Program Evaluation Manual," Florida Department of Transportation. http://www.nctr.usf.edu/clearinghouse/pdf/capman\%20rev\%202.pdf

[9] Eric N. Schreffler, ESTC (2003), "Quantification Methods for Identifying Emission Reductions Resulting from Seasonal and Episodic Public Education Programs," California Air Resources Board. Accessed February 2110 at http://www.arb.ca.gov/research/apr/past/98-318.pdf

[10] National Center for Transit Research at Center for Urban Transportation Research, University of South Florida (2007), "Impact of Employer-Based Programs on Transit System Ridership and Transportation System Performance," Florida Department of Transportation. Accessed January 2010 at http://www.nctr.usf.edu/pdf/77605.pdf

[11] Mike Spack, Mike Bultman, Kirk Pettis, Jenni Thompson, and Joe Collins (2010), "An Analysis of the Effectiveness of TDM Plans in Reducing Traffic and Parking in the Minneapolis-St. Paul Metropolitan Area," Spack Consulting. Accessed February 2010 at http://mikeontraffic.typepad.com/files/traveldemand-management-effectiveness-report.pdf

[12] Sisinnio Concas and Philip L. Winters, National Center for Transit Research at Center for Urban Transportation Research, University of South Florida (2009), "Quantifying Net Social Benefits of Vehicle Trip Reduction Impacts to Make Existing Road Infrastructure Perform Better- Guidance for Customizing the TRIMMS Model to Aid Local, Regional and State Decision Makers," Florida Department of Transportation. Accessed January 2010 at http://www.nctr.usf.edu/pdf/77805.pdf

[13] Sara J. Hendricks, (2005), Effectiveness of Programs for Work Site Trip Reduction - The Influence of Organizational Culture, Journal of the Transportation Research Board, Vol. 1924, pp. 207-214. 
To measure the impact of employer-based TDM programs on transport networks in an effective and efficient manner, it is desirable to establish a proper linkage between the travel demand model and TDMAP. For example, a trip-based travel demand model such as FSUTMS (Florida Standard Urban Transportation Model Structure) produces multiple origin-destination (O/D) tables as a result of the Home-Based Work Mode Choice Model (Figure A1). The O/D table can be rearranged into the proper format for processing by a TDM impact assessment tool such as TRIMMS or EPA commuter model. This particular approach adopts TRIMMS.

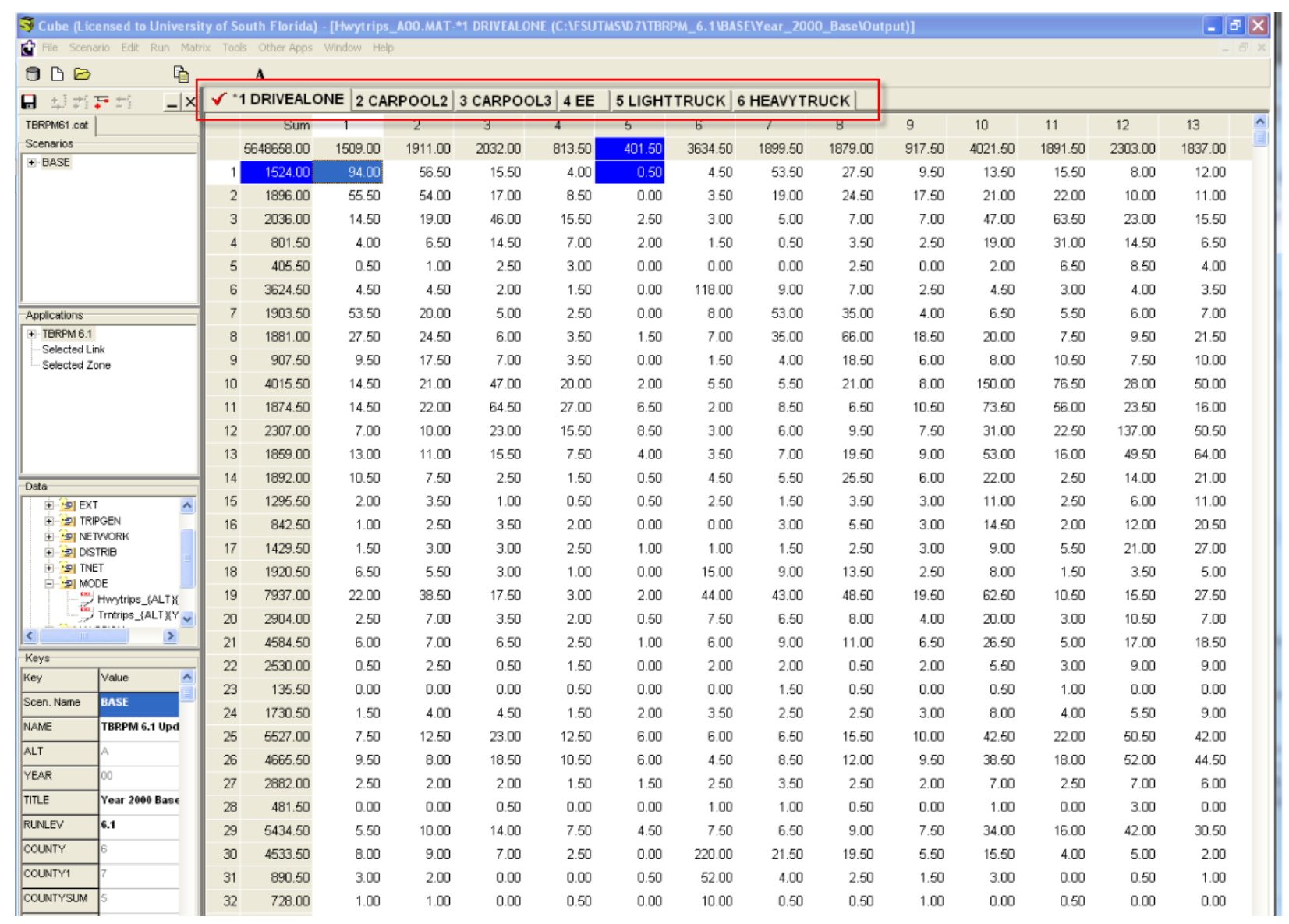

Figure A1 - 0/D Tables after Mode Share in FSUTMS 
Assume that the following O/D tables can be obtained for AM Home-Based work trips in FSUTMS:
1) AM_sov_hbw
2) AM_hov_2 (AM Peak Period HOV 2)
3) AM_hov_3 (AM Peak Period HOV 3 or 3+)
4) AM_transit (AM Peak Period Public Transit)
5) AM_bike (AM Peak Period Public Transit)
6) AM_walk (AM Peak Period Walk)

First, O/D tables will be imported to the "Modeshare Update" tool and aggregate to compatible modes in TRIMMS. TRIMMS currently has the following predefined modes:
1) Auto - Drive Alone
2) Auto - Rideshare
3) Vanpool
4) Public Transport
5) Cycling
6) Walking
7) Other

Second, mode share at each targeted destination zone will be calculated and put into the proper format which can be compatible to run TRIMMS ${ }^{\complement}$ in batch process. TRIMMS estimates mode share changes per each zone based on various inputs and assumptions, as discussed in the previous chapter.

Third, the "Modeshare Update" process will distribute the estimated mode share changes to associated origin zones. The aggregated O/D tables will be updated first and this will be disaggregated to the initial O/D tables which can be fed back into Travel Demand Model. The following section presents a step-by-step demonstration on using "Modeshare Update."

\section{Step 1: Import and Aggregate O/D Tables}

Modeshare Update_v_1.0.xIsm has two default worksheets in the tool named "Control Panel" and "Modeshare@Destination." O/D tables by mode (from travel demand model) can be added into the tool. Each worksheet will hold an O/D table by mode. For example, if the travel demand model produces 11 different O/D tables based on modes, then 11 worksheets will be added to the tool.

1. The tool reads only worksheets labeled "*.od" to be recognized by the tool as O/D.

2. *.od automatically will be registered as an O/D table. User adds "worksheet" names of modes that need to be aggregated. The worksheet names are available in the drop-down box. For example, modes \#1 to \#11 are added in the worksheet column.

3. User specifies the name of the aggregated mode under which individual modes will be aggregated. For example, 11 modes of O/D tables are aggregated under the mode name "Transit." 
Click on "Aggregate" (in the "Control Panel" worksheet), and a new worksheet corresponding to the names given in the previous steps is created. For example, two new worksheets with "AutoRT.od" and "Auto-DA.od" are created containing the aggregated data.

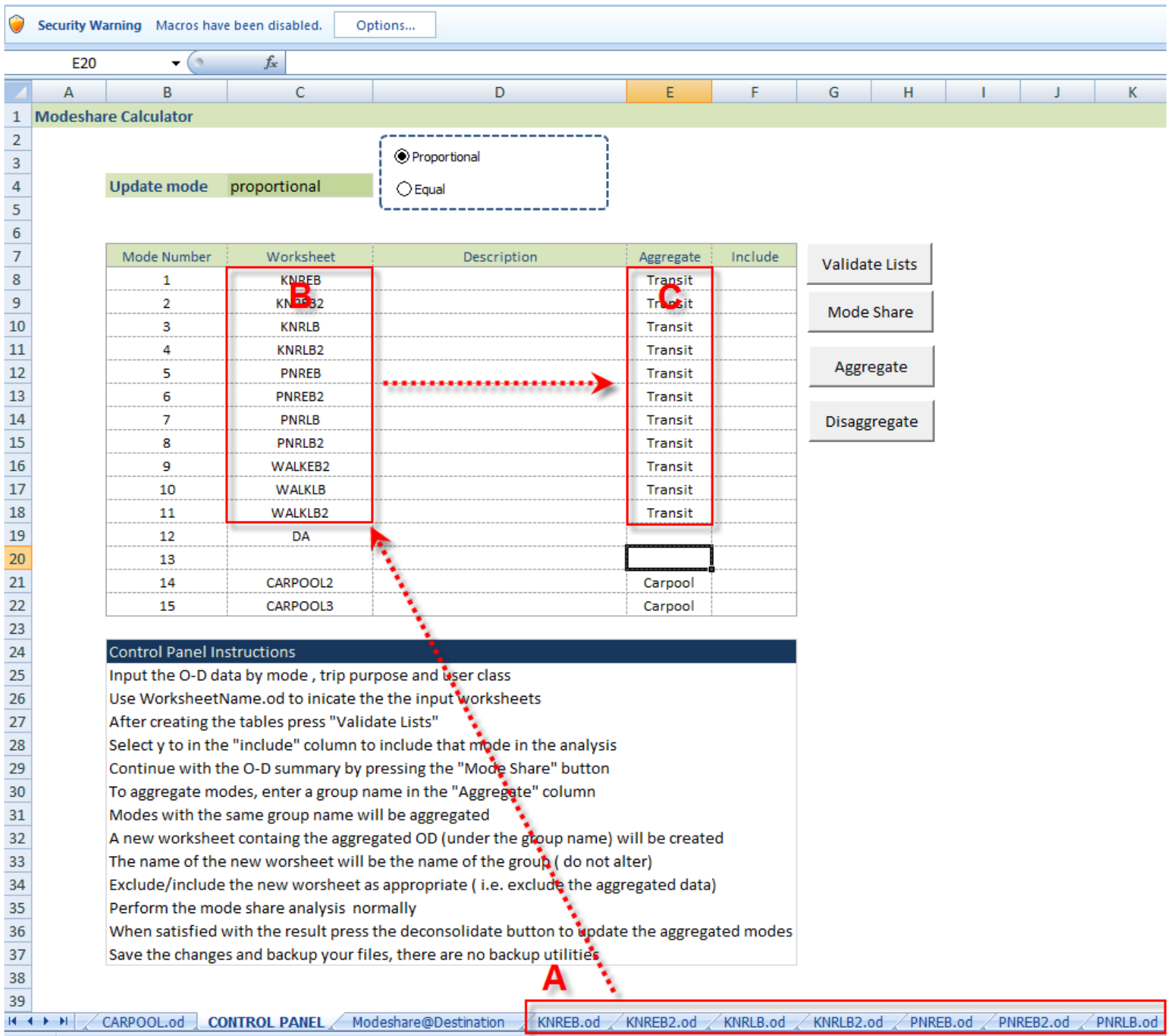

Figure A2 - Modeshare Update Starting Screen

\section{Step 2: Aggregate Existing 0/D Tables}

Add the newly-created worksheets and other modes that do not require aggregation. Make sure the sequence of mode names is the same as it appears in TRIMMS ${ }^{\odot}$ 2.0. For example, add "Transit" and "Carpool" (newly-created worksheets) and "Transit" (in this order). "Walk" and "Other"' would follow if used in the FSUTMS model.

Select $Y$ to include the modes to be inputted in TRIMMS ${ }^{\odot} 2.0$ for analysis and click "Mode Share," Figure A3. 


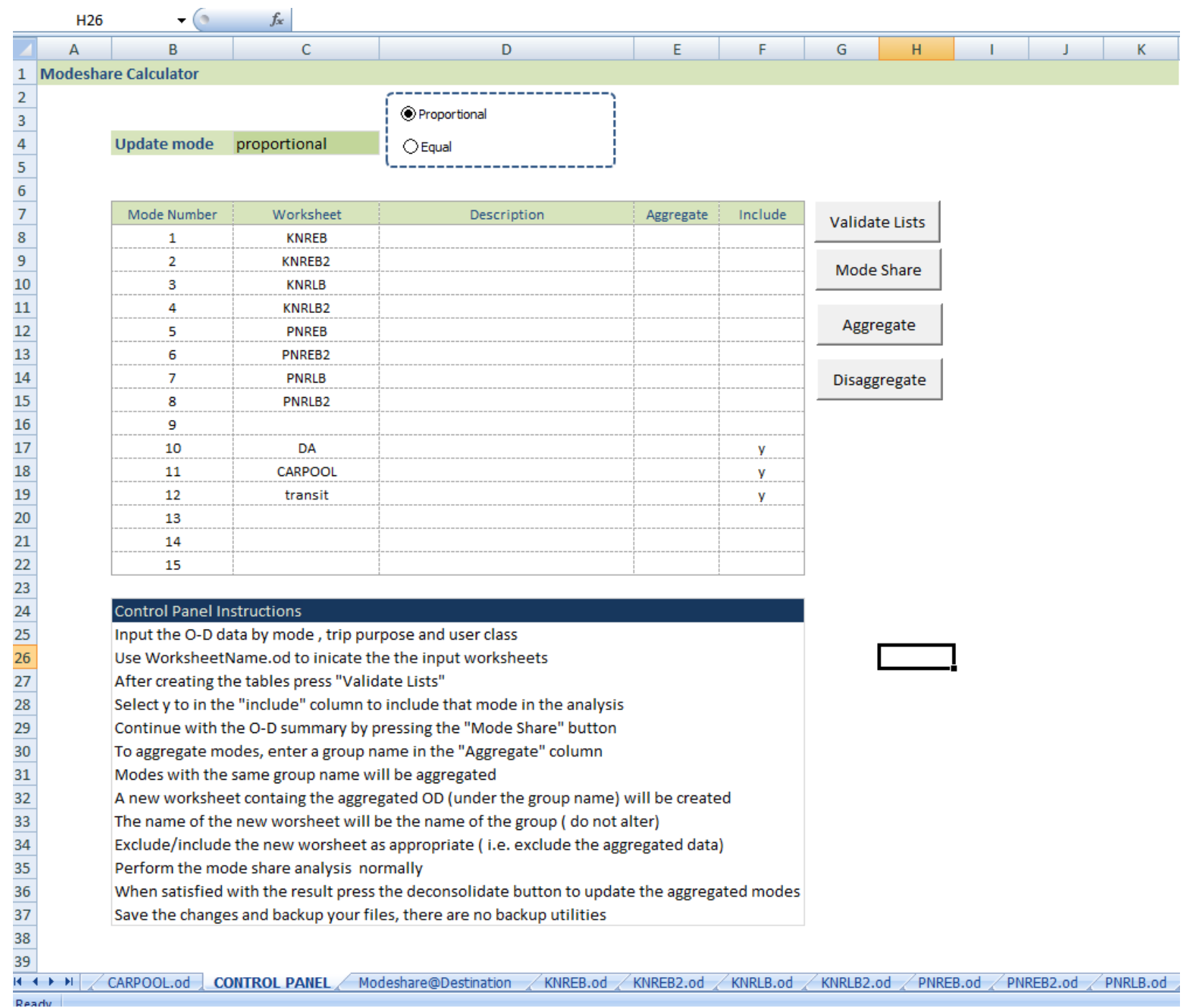

Figure A3 - Calculation of Mode Share

Step 3: Open Mode Share by Destination Zones

Open the "Mode@Destination" tab, Figure A4, and the aggregated mode share will be available to run TRIMMS ${ }^{\odot}$ 2.0. Columns A-F, starting with row 2, can be copied and pasted directly into column $C$ and columns AR-AV of the ScenarioSheet part of the TRIMMS ${ }^{\odot} 2.0$ batch processor. 


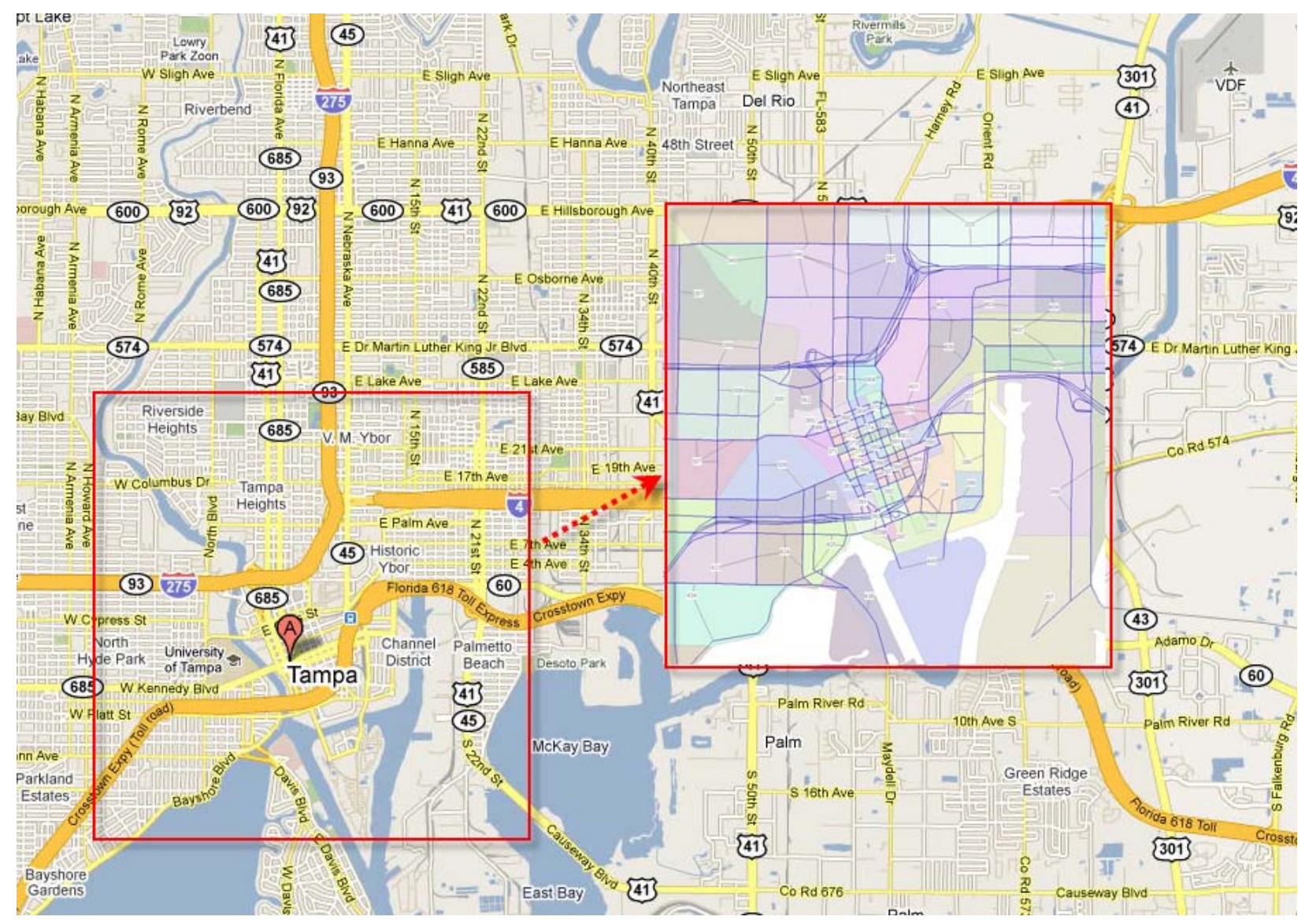

Figure A4 - Study Area and TAZ

Depending on the study area, target TAZs will be selective. For example, if the purpose of study is to alleviate traffic congestion at Downtown Tampa, then the corresponding TAZ 362 to 400 will be used as destination zones. 


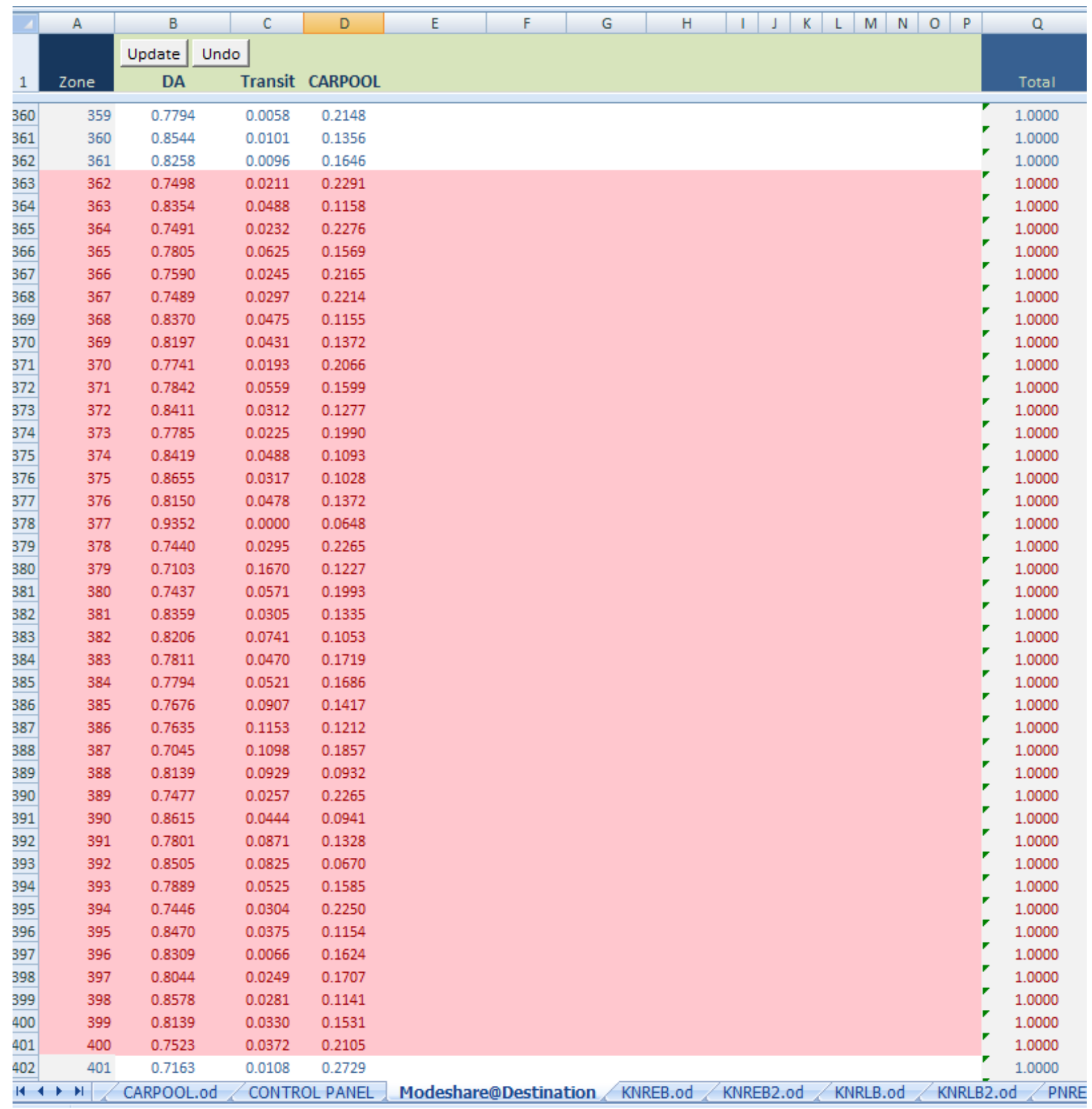

Figure A5 - Aggregated Mode Share

Note: By following the above steps, mode share has been aggregated into modes suited for TRIMMS $^{\complement} 2.0$ analysis.

\section{Step 4: Run TRIMMSC 2.0}

Although TRIMMS ${ }^{\odot} 2.0$ could be run manually for each TAZ, this would be burdensome for estimating changes in a large number of traffic analysis zones (TAZs). The batch processor is designed to reduce this burden by enabling the user to use software to compile and format the input data, copy the data in to the batch processor, run TRIMMS ${ }^{\complement} 2.0$ for each TAZ, and save 
the results in a machine-readable form for further analysis. The batch processor is embedded within the TRIMMS $^{\oplus} 2.0$ workbook, and acts as a "shell" around the TRIMMS $^{\oplus} 2.0$ calculations.

Use of the batch processor requires entering or copying data into a spreadsheet, one row for each TAZ. The data to be entered include an identifier for each TAZ; the mode split for persontrips arriving in the TAZ, as estimated by the regional transportation model, generally from a run of the regional model; and a variety of optional information about the those trips and about TDM elements intended to modify the mode split. The batch processor clears previous results from the output spreadsheet; reads the data provided for each TAZ/row; transfers it to TRIMMS $^{\odot}$ 2.0, which estimates the change in the mode split; and then copies the TAZ identifier and changed mode split into an output spreadsheet, from which the results for all TAZs can be copied and fed back into the regional model.

TRIMMS $^{\oplus} 2.0$ processes each destination TAZ independent of all other TAZs. Therefore, it is not necessary to run every destination TAZ from the regional model through TRIMMS ${ }^{\odot} 2.0$ if the TDM program being analyzed applies only to a subset of the region's TAZs (for example, destinations within a specific transportation corridor of interest). It also is not necessary to set the same TDM policy for all TAZs being processed in a run of the batch processor. If, for example, the analysis is to estimate the effects of imposing payment for parking, and such payments already exist in some TAZs but at a level different than what is being proposed, then fees can be set to reflect existing or planned variation in the price of parking. Finally, it is not necessary to set values for all of the TDM options available to the analyst. For example, if a TDM strategy focuses on parking, and no changes are proposed for other program elements (such as subsidies for the use of alternative modes), only the values pertaining to parking need to be entered, and the remaining values should be left blank.

Once the data have been entered, the batch processors will then feed each TAZ's data into TRIMMS $^{\oplus} 2.0$, calculate results, and save them.

\section{Step 5: Import the Result of TRIMMS(C) 2.0}

Revised mode shares obtained from the "Saved Results" spreadsheet in the TRIMMS 2.0 batch processor should be pasted into columns B-F of the "Modeshare@Destination" worksheet and then click "Update." This will update the aggregated O/D tables. The mode share change by destination zone will be distributed across all associated origin zones proportionally. However, there is no existing trip per mode between O/D pairs; the O/D pairs will not be affected by change of mode share.

\section{Step 6: Update O/D Tables}

The updated O/D tables can be exported and used by travel demand model professionals for traffic assignment. Depending on the travel demand model, it may be necessary to reformat the tables. With the completion of traffic assignment, the impact of TDM programs on the transport network can be quantified with various measures. 


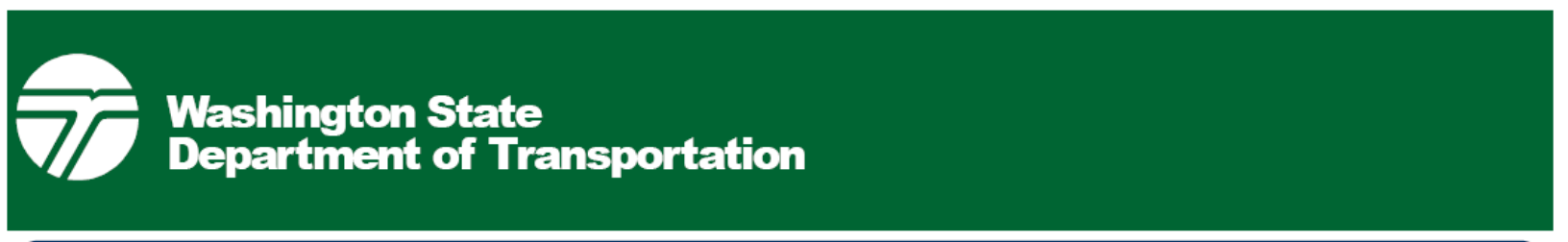

\section{CTR Employer Cost Survey}

The Washington State Legislature requires the Department of Transportation to report on how much employers spend on complying with the state's Commute Trip Reduction (CTR) program and working toward the program's objectives. WSDOT does this by surveying employers every two years to ask them how much they spend on various activities related to the program, and how much of this is from the employer and how much from other sources.

Please take just a few minutes to complete this short form and return it in the stamped return envelope provided. The Legislature is interested in totals and general types of costs - not in details. The categories we provide in this survey are designed to help you organize information. Use your best judgment when determining the appropriate categories for various expenses.

\section{Part 1 - Information About Your Organization}

1 Which organization or worksite(s) are you reporting on in this survey? (If you administer the CTR Program at more than one worksite you can combine the costs and report them all on this form. Just make sure to list all worksites you are reporting for in the space provided below.)

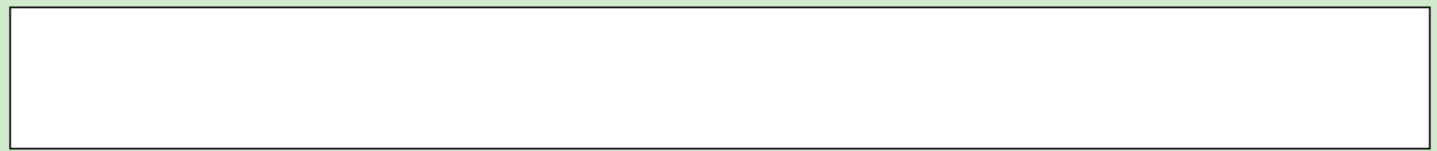

We are asking the next three questions in order to help us contact you in case we need further clarification with your responses. This survey is completely confidential and this information will not be reported to anyone outside of the CTR survey staff.

2 What is your name?

3 What is your Area Code and phone number?

4 What is your email address?

5 What is today's date?

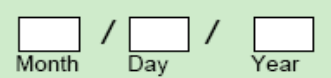

The next two questions ask for the start and end date of your CTR program Cost Period. This is the 12-month period in which you will be estimating your organization's Total Yearly Costs in the table on the next page. It would be most helpful to us if you can report for the period of July 1, 2005 through June 30, 2006. However, some organizations may find it easier to report for a different 12-month period.

6 What is the start of your Cost Period?

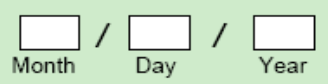

7 What is the end of your Cost Period?

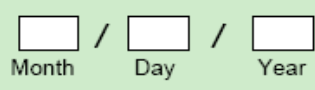




\section{Part 2 - CTR Program Costs}

8 For each activity in the table below, please tell us how much cost your organization has incurred for supporting and overseeing your CTR program during the 12 -month cost period you have described on the previous page. Please give us an estimate of monetary costs, in-kind costs and an estimate total cost for the year.

Monetary Cost Estimate: We are asking about the value of goods and services that your organization contributed in order to administer the CTR Program. Examples of this type of cost include your organization's staff time spent administering the CTR Program and any dues paid to local Transportation Management Associations (TMAs).

In-Kind Cost Estimate: This is the value of goods and services contributed from sources outside your organization. However, please don't include contributions from local governments or transit agencies. We already have this information from the local governments and transit agencies. Examples of this type of cost inciude donated gift certificates, staff time from local bike shops for workshops held at your organization, and any donated merchandise.

Type of Activity $\quad \begin{gathered}\text { Monetary Cost } \\ \text { Estimate }\end{gathered} \quad \begin{gathered}\text { In-Kind Cost } \\ \text { Estimate }\end{gathered} \quad \begin{gathered}\text { Total Yearly Cost } \\ \text { Estimate }\end{gathered}$

Promoting the CTR Program to employees

(Including ETC time, supplies, etc.)

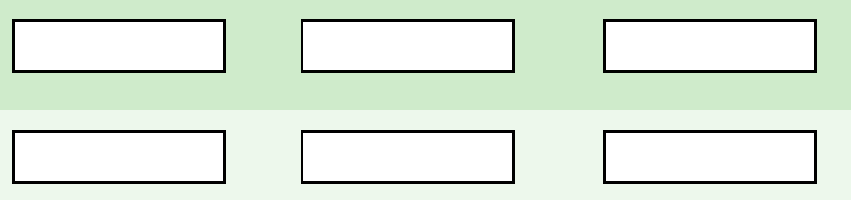

Helping employees with transportatio questions, such as transit schedules. arranging carpools and vanpools
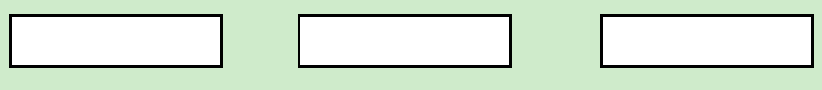

employees, such as guaranteed ride home. shuttle bus, etc.
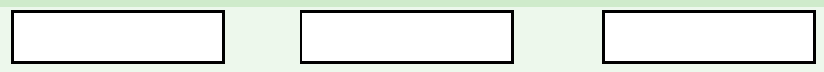

Financial ince
to employees.
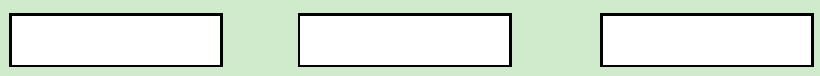
lockers, etc. (including current expenses only.)
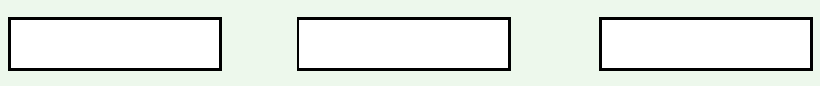
incentive payments, in meetings, conducting surveys, completing annual reports, etc.)

Any other costs that are not covered in the categories above (please describe in in question 9 below)
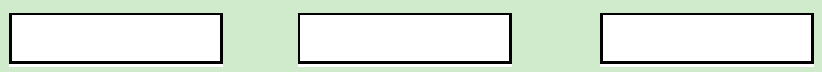

9 Thank you for your time in responding to the 2006 Employer CTR Cost Survey. If you have any additional comments about the CTR Program or this survey. please feel free to note them here.

Please send your completed survey back in the postage-paid retum envelope that was provided. You may also fax this form to (509) 335-0116, if you prefer.

If you have any questions about this survey, you may call

Thom Allen at 1-800-833-0867 or send email to ted@wsu.edu 